\title{
¿Effects of Nonuniform Land Surface Warming on Summer Anomalous Extratropical Cyclone Activity and the East Asian Summer Monsoon: Numerical Experiments with a Regional Climate Model
}

\author{
WANXIN ZhANG, ${ }^{\text {a,b,c }}$ Haishan Chen, ${ }^{\text {a,b,d }}$ Liming Zhou, ${ }^{\mathrm{c}}$ Botao Zhou, ${ }^{\mathrm{a}, \mathrm{b}}$ JiE ZHANG, ${ }^{\mathrm{a}, \mathrm{b}}$ AND JiANGFENG WeI ${ }^{\mathrm{a}, \mathrm{b}}$ \\ ${ }^{a}$ Key Laboratory of Meteorological Disaster, Ministry of Education/International Joint Research Laboratory of Climate and \\ Environment Change/Collaborative Innovation Center on Forecast and Evaluation of Meteorological Disasters, Nanjing University \\ of Information Science and Technology (NUIST), Nanjing, China \\ ${ }^{\mathrm{b}}$ School of Atmospheric Sciences, NUIST, Nanjing, China \\ ${ }^{\mathrm{c}}$ Department of Atmospheric and Environmental Sciences, University at Albany, State University of New York, Albany, New York \\ ${ }^{\mathrm{d}}$ NUIST-University of Reading International Research Institute, NUIST, Nanjing, China
}

(Manuscript received 11 February 2020, in final form 20 August 2020)

\begin{abstract}
Previous studies detected significant negative correlations between the nonuniform land surface warming and the decadal weakened activities of the summer extratropical cyclones (ECs) over East Asia and the East Asian summer monsoon (EASM) after the early 1990s. Here such relationships are further examined and the possible mechanisms are explored via numerical sensitivity experiments with a regional climate model (RegCM4.5). The positive/negative sensible heat flux ( $\mathrm{SH}$ ) anomalies were added as a forcing to a key region near $50^{\circ} \mathrm{N}$ of East Asia in RegCM4.5 to simulate the observed ground surface temperature (GST) anomalies. The model results suggest that the nonuniform land surface warming over the Lake Baikal area $\left(50^{\circ}-60^{\circ} \mathrm{N}, 90^{\circ}-120^{\circ} \mathrm{E}\right)$ can indeed cause the weakening of the extratropical cyclogenesis and affect the decadal weakening of the EASM. Warm (cold) GST forcing over the key GST region can lead to decreasing (increasing) atmospheric baroclinicity and related energy conversion of the EC activity over the key EC region $\left(40^{\circ}-50^{\circ} \mathrm{N}\right.$, $90^{\circ}-120^{\circ} \mathrm{E}$ ), resulting in an evidently weakening (enhancing) of the ECs over East Asia. Meanwhile, precipitation shows a dipole pattern with significantly suppressed (enhanced) precipitation in northern and northeastern China, and slightly enhanced (suppressed) rainfall south of $40^{\circ} \mathrm{N}$ of East Asia, mainly over the East China Sea. Lake Baikal and its adjacent areas are occupied by a strong anticyclonic (cyclonic) circulation while the southeast coastal areas of China have a relatively weak cyclonic (anticyclonic) circulation accompanied with an anomalous northeasterly (southwesterly) wind to the southeast of the anticyclonic circulation, which is opposite to (coincident with) the atmospheric circulation anomalies that are associated with the second mode of the EASM.
\end{abstract}

KEYWORDS: Atmosphere-land interaction; Extratropical cyclones; Baroclinic flows; Land surface; Monsoons

\section{Introduction}

In the context of global warming, the land surface warming rate exhibits significant geographic nonuniformity (Hansen et al. 2006, 2010; Zhou et al. 2015, 2016). The significant warming trend and the rapid decadal summer warming over the Eurasian continent have received much attention (Sutton and Dong 2012; Stainforth et al. 2013; Dong et al. 2017). Previous studies detected a nonuniform spatial pattern of summer land surface warming around the mid-1990s over the Eurasian continent, with a predominant amplified warming over Europe-West Asia and Northeast Asia (Chen and Lu 2014; Dong et al. 2016; Chen et al. 2017b; Hong et al. 2017). This regional warming feature has been explored in recent studies (Zhu et al. 2012; Han et al. 2016).

Since the Eurasian continent is the largest continent in the world, with complex terrain and diverse underlying surface conditions, the land surface thermal anomalies over different

¿ Denotes content that is immediately available upon publication as open access.

Corresponding author: Haishan Chen, haishan@nuist.edu.cn regions of Eurasia are expected to have nonnegligible impacts on both the atmospheric general circulation and climate via land-atmosphere interactions (Vernekar et al. 1995; Dong and Valdes 1998; Dash et al. 2006). For instance, Chen et al. (2016) investigated the interannual variations of summer surface air temperature over Northeast Asia (NEA) and its associated circulation anomalies. They obtained two leading modes by EOF analysis: 1) a homogeneous temperature anomaly over NEA centered over Northeast China, which is called the NEA mode, and 2) a seesaw pattern showing a contrasting distribution between East Asia and north of this region, which is named the East Asia (EA) mode. Their results indicated that abnormal summer surface air temperature over NEA has significant impacts on the upper-tropospheric westerly jet, and also that the NEA mode is associated with the Eurasian teleconnection pattern, whereas the EA mode is associated with the East Asia-Pacific/Pacific-Japan pattern. Lin et al. (2018) found a close relationship between the surface air temperature in the Russian Far East area and the northern flank of the East Asian upper-tropospheric westerly jet (EAJ), which could be explained by a positive feedback mechanism between the surface air temperature in the Russian Far East area and the overhead circulation: when the surface air temperature in the Russian Far East area is warmer than usual, there is a local 
anticyclonic circulation anomaly in the upper troposphere that will decelerate the westerly in the northern flank of the EAJ, and the anticyclonic circulation anomaly related to the weakened westerly in the northern flank of the EAJ can in turn induce a warmer surface. Yan et al. (2019) evaluated the simulations of the meridional displacement of the EAJ, which is the dominant interannual variation mode of the EAJ in observations, using 34 CMIP5 CGCMs. Their study proved the interannual relationship between the EAJ meridional displacement and East Asian summer rainfall, which is recognized as the main linkage between extratropical circulation anomalies and East Asian summer rainfall in observations. In addition, the warming of Eurasia could also play a role in shaping the monsoon and thereby causing drought in northern China. J. Zhang et al. (2019) identified the linkage of Eurasian warming with extreme summertime droughts in northern China, related to both monsoon circulation and westerly circulation. Their study pointed out that increasing Eurasian heating contributes to the enhancing Eurasian teleconnection pattern (EU) and Silk Road pattern (SRP): positive anomalies of the EU and SRP patterns lead to coincident anticyclone anomalies and an enhanced ridge around Lake Baikal and northern China, which finally result in downward motion and divergence and are responsible for the extreme summertime droughts in northern China.

Extratropical cyclones (ECs) are large, mid- to high-latitude, low pressure vortices with strong baroclinicity that are closely related to the large-scale circulation in the Southern and Northern Hemispheres. The anomalous activity of ECs has been extensively studied for decades. A number of studies documented evident changes in the frequency and other statistics of the cyclone during recent decades. Analyses of Northern Hemisphere cyclones showed secular and decadal-scale changes in cyclone frequency, intensity, lifetime, and deepening rates to various extents (Gulev et al. 2001). Wang et al. (2006) defined strong cyclones as cyclones with intensity of $15 \times 10^{-5} \mathrm{hPa} \mathrm{km}^{-2}$ or greater, and showed a significant increasing trend in JanuaryMarch (JFM) strong-cyclone activity over the high-latitude North Atlantic and over the midlatitude North Pacific, with a significant decreasing trend over the midlatitude North Atlantic and a small increasing trend over northern Europe. McCabe et al. (2001) indicated a statistically significant decrease in midlatitude cyclone frequency and a significant increase in high-latitude cyclone frequency. Their study supported the hypothesis that global warming may result in a northward shift of storm tracks in the Northern Hemisphere. Wang et al. (2009) proved that the dipole structure of EC changes, with increases in the north and decreases in the southern part of northern East Asia, is related to the northward movement of the baroclinic frontal zone on either side of $110^{\circ} \mathrm{E}$.

In the Northern Hemisphere, the main cyclone activity occurs primarily over the North Atlantic and the North Pacific, and secondarily over the Asian continent and the Mediterranean region (Ulbrich et al. 2009). Nevertheless, a series of recent studies focus on the EC activity over East Asia. Wang et al. (2009) revealed that EC activity has displayed clear seasonal, interannual, and decadal variability in northern East Asia and the frequency of ECs has increased in the high latitudes (especially $40^{\circ}-50^{\circ} \mathrm{N}$ ) of East Asia, which is opposite to the lower latitudes during the period 1958-2001. This north-south dipole structure of trends in East Asian summer EC is also obvious in the more recent analysis of Rudeva and Simmonds (2015). Other studies (Wu et al. 2010) also noted that the frequency of the EC activity evidently decreased after the early 1990s. For a long time, much effort has been made to explain the anomalous activity of ECs and its decadal change. H. Zhang et al. (2019) detected a significant interdecadal increase in the seasonal mean Mongolian sea level pressure (MSLP) around the early 1990s, which was accompanied by a weakening in the activity of regional ECs, and suggested that the inhomogeneous air temperature anomaly distribution may be responsible for it. Since atmospheric baroclinicity, which has long been regarded as a main triggering mechanism of the midlatitude synoptic-scale weather system, is closely related to the meridional temperature gradient (Simmons and Hoskins 1978; Hoskins and Valdes 1990; Lim and Simmonds 2002, 2007), the effect of the land surface warming nonuniformity to the EC activity is supported by a number of observation-based analyses.

Chen et al. (2017b) pointed out that there is a close linkage between the weakening of the midlatitude summer cyclonic activity over East Asia after the early 1990s and the decadal variation of East Asian summer monsoon (EASM). When the midlatitude summer cyclone activity over East Asia is strong (weak), EASM tends to be intensified (weakened). Chen et al. (2017b) conjectured that significant warming to the west of Mongolia tends to weaken the north-south temperature gradient and the atmospheric baroclinicity to its south and thus leads to weakening of the midlatitude cyclone activity over East Asia. In a more recent study, Chen et al. (2019) investigated the impact of nonuniform land surface warming on the summer anomalous EC activity over East Asia and further explored their negative correlation and possible physical mechanisms.

Although many studies have showed that the surface warming nonuniformity did play an important role in affecting the anomalous EC activity, they were based on empirical statistical methods, which cannot tell the causality and the underlying mechanism, and thus should be corroborated by numerical model experiments, which can better quantify and separate various relevant physical processes. With this in mind, as a sequel to Chen et al. (2017b) and Chen et al. (2019), here we aim to explore numerically the mechanism for the role played by the land surface thermal anomaly in affecting the summer variation of EC activity over the midlatitude of East Asia and EASM. The structure of this paper is as follows: section 2 describes the data and model used in this study. The results of model sensitivity experiments are presented in section 3 , followed by conclusions and discussion in section 4 .

\section{Data and methods}

\section{a. Observation and reanalysis data and methods}

The reanalysis data used in this study are from the European Centre for Medium-Range Weather Forecasts interim reanalysis (ERA-Interim; Dee et al. 2011; http://apps.ecmwf.int/ datasets/) data and the 6-hourly NCEP Reanalysis 2 data 
provided by the National Centers for Environmental PredictionDepartment of Energy (NCEP-DOE; Kanamitsu et al. 2002; https://psl.noaa.gov/), with a horizontal resolution of $1.5^{\circ} \times 1.5^{\circ}$ (ERA-Interim) and $2.5^{\circ} \times 2.5^{\circ}(\mathrm{NCEP}-\mathrm{DOE})$, including topography and the monthly mean fields of geopotential height, horizontal wind and 6-h daily sea surface pressure. The monthly mean temperature data used include the land skin temperature from ERA-Interim, and the near-surface temperature (version 4.03) from the Climatic Research Unit (CRU), University of East Anglia, United Kingdom (Harris et al. 2014). The monthly mean precipitation data are the GPCC Full Data Monthly Product version 2018 (GPCC; Schneider et al. 2018) and the CRU TS4.03 dataset. The spatial resolution is $0.5^{\circ} \times 0.5^{\circ}$ for the CRU data and $0.25^{\circ} \times 0.25^{\circ}$ for the GPCC data, and the time period investigated is 36 years (1982-2017) for CRU and 35 years (1982-2016) for GPCC. The monthly mean soil moisture, surface sensible heat flux and surface latent heat flux data are from the NCEP-NCAR reanalysis project (NCEP-NCAR1; Kalnay et al. 1996; https:// psl.noaa.gov/), the NCEP-DOE Reanalysis 2 data (NCEPDOE), the Modern-Era Retrospective Analysis for Research and Applications version 2 (MERRA-2; Gelaro et al. 2017), and the Global Land Data Assimilation System Noah land surface model dataset version 1 (GLDAS-1; Rodell et al. 2004). The time period investigated is 39 years (1979-2017) for NCEP-NCAR1, NCEPDOE, GLDAS-1, and 38 years (1980-2017) for MERRA-2.

The objective identification and tracking algorithm used to track cyclones was proposed by Murray and Simmonds (1991a,b) and refined by Simmonds and Murray (1999), which has been widely used in the research of extratropical cyclone (Lim and Simmonds 2007; Pezza et al. 2012). The definition of cyclogenesis frequency was given by Chen et al. (2017b), which refers to the number of cyclones generated in each $1.5^{\circ} \times 1.5^{\circ}$ grid box.

The maximum covariance analysis (MCA) for July ECs and GST is performed to confirm the negative correlation between EC activity and GST in the summer season. The trend and mean of the time series of July ECs and GST during 1979-2017 are removed before performing the MCA. The time series was standardized via dividing it by its standard deviation first, followed by the MCA. For example, MCA1 for July ECs and GST is shown in Fig. 1, which explains about $40.3 \%$ of the covariance. Here we locate two key regions of interest based on MCA1: 1) the key region of GST anomaly $\left(50^{\circ}-60^{\circ} \mathrm{N}, 90^{\circ}-\right.$ $120^{\circ} \mathrm{E}$, delineated by the solid rectangle in Fig. 3), where the GST anomaly affects the anomalous EC activity most in the midlatitude of East Asia, referred to as the key GST region, and 2 ) the key region of EC activity $\left(40^{\circ}-50^{\circ} \mathrm{N}, 90^{\circ}-120^{\circ} \mathrm{E}\right)$, which shows the maximum frequency and significant variability of EC activity (figure not shown), referred to as the key EC region. The MCA for July ECs and GST before detrending supports a similar conclusion (figure not shown), implying that GST over the key GST region is closely related to the EC activity over the key EC region. Figure 1d shows the normalized time series of regional averaged summer mean and July GST over the key GST region, and ECs over the key EC region. For visual clarity the normalized time series of regional averaged of summer mean (JJA) and July GST of the key GST region in Fig. 1d are multiplied by -1 . The correlation coefficients between July ECs activity and GST are -0.57 , and -0.59 for the summer mean. Both pass the $t$ test at the 0.05 confidence level. The significant correlations remain after the linear trend are removed from the data, with the correlation coefficients being -0.46 and -0.38 for July and the summer mean, respectively. The consistent variations among them and their correlation coefficients confirmed the negative correlation between EC activity and GST for both summer mean and July, and July can well represent the situation in the summer season. We further performed an EOF analysis on July GST and SH before and after removing the linear trends. Figures $1 \mathrm{e}$ and $1 \mathrm{~g}$ show the spatial distribution of the first EOF mode of GST and SH over East Asia before detrending, and there is a distinct center of positive anomalies for both GST and $\mathrm{SH}$ in the midlatitude of East Asia. The principal component (PC1) of GST and SH before detrending both show a clear decadal change after the early 1990s. The correlation coefficients between the PC1 of July GST and SH is 0.67 that passes the $t$ test at the 0.05 confidence level. The EOF analysis of the detrended GST and SH shows the same spatial pattern with positive anomalies over the midlatitude of East Asia (figure not shown), and the correlation coefficients between the PC1 of detrended July GST and SH is 0.63 , which also passes the $t$ test at the 0.05 confidence level. In addition, we also performed an EOF analysis on July ECs and then calculated its PC1 correlation coefficients with the PC1 of SH and GST. The correlation coefficients between the PC1 of July ECs and SH are -0.35 and -0.42 before and after removing the linear trends. The PC1 of ECs and GST also shows significant correlations with the correlation coefficients being -0.43 and -0.47 before and after removing the linear trends. All the correlation coefficients mentioned above passed the $t$ test at the 0.05 confidence level and confirmed the negative correlation between SH, GST, and EC activity. The consistent variations and significant correlation before and after removing the linear trends indicate a close linkage between ECs, GST, and SH, and the analyses above indicates the robustness of this link.

Before the numerical experiments, we have checked the land surface parameters (e.g., soil moisture, surface albedo, and NDVI) that may potentially affect the GST in the key GST region and found that there is a significant positive correlation between the spring soil moisture in western Siberia to the Lake Baikal area and the summer GST anomalies in the key GST region; also, the soil moisture has a good memory that can sustain to summer. Besides the nonlocal effects, the local land surface thermal conditions also play an important role. Figure 2 shows the spatial distribution of the linear trend of summer soil moisture, surface sensible heat flux, and surface latent heat flux over the East Asia in four reanalyses. The four datasets reflect consistent characteristics of the variations in the soil moisture, surface sensible heat flux, and surface latent heat flux. Both the soil moisture and surface latent heat flux are evidently decreasing. There is an obvious increasing trend in the surface sensible heat flux over East Asia for the period 1979-2017. Figure 2 shows that drier soil with reduced latent heat and intensified sensible heat may lead to the land surface warming in the midlatitudes of East Asia. The role of local atmospheric forcing and land-atmosphere interaction responsible for recent 

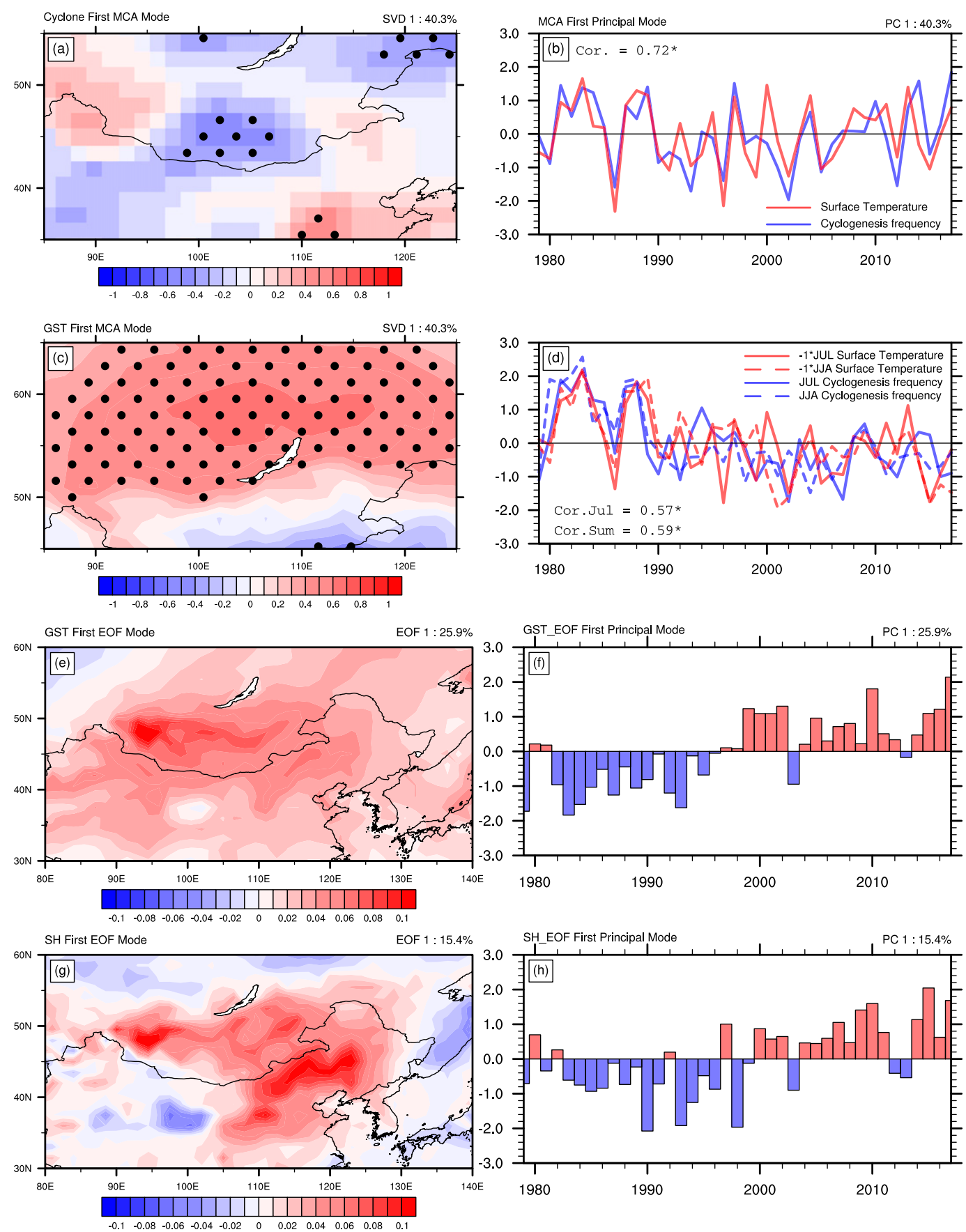

FIG. 1. MCA over midlatitude region of East Asia with the detrended data. (a),(c) Heterogeneous correlation coefficient of MCA1 for July cyclogenesis frequency over the key EC region and GST over the key GST region, respectively. The black dots in (a) and (c) indicate correlation coefficients are statistically significant at the 0.05 level. (b) PC1 of MCA during 1979-2017 for July cyclogenesis frequency (blue line) and GST (red line). (d) Normalized time series of regional averaged of summer mean (JJA) and July GST of the key GST region, and ECs over the key EC region. Also shown are the EOFs over the midlatitude region of East Asia with the original data: the (e),(g) spatial pattern and (f),(h) normalized time series of the first EOF mode (PC1) of July GST and SH. For visual clarity the normalized time series of regional averaged of summer mean (JJA) and July GST of the key GST region in Fig. 1d are multiplied by -1 . 

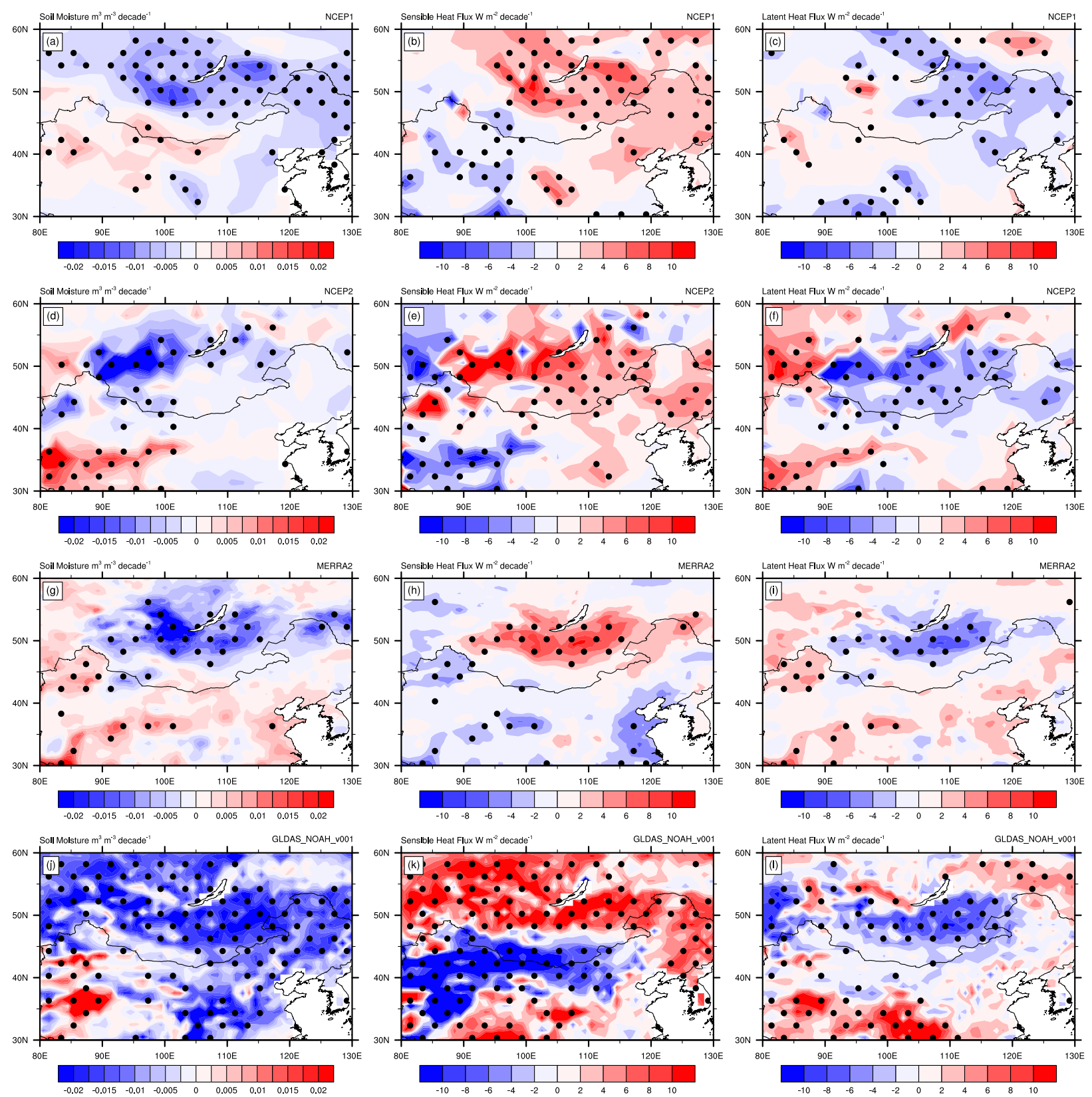

FIG. 2. Linear trend of summer mean (JJA) (left) surface soil moisture $\left(\mathrm{m}^{3} \mathrm{~m}^{-3} \mathrm{decade}^{-1}\right.$ ), (center) surface sensible heat flux ( $\left.\mathrm{W} \mathrm{m}^{-2} \mathrm{decade}^{-1}\right)$, and (right) surface latent heat flux $\left(\mathrm{W} \mathrm{m}^{-2} \mathrm{decade}^{-1}\right.$ ) for the period 1979-2017 of (a)-(c) NCEP-NCAR1, (d)-(f) NCEP-DOE, and (j)-(l) GLDAS-1, and (g)-(i) the period 1980-2017 of MERRA-2. The black dots indicate the anomalies are statistically significant at the 0.05 level.

summer land surface warming over East Asia and the possible mechanisms have been proved by our previous work (Chen et al. 2020).

\section{b. Model and experiments}

To further explore the relationship between GST and EC activity, a numerical case study was carried out using the RegCM4.5 (http://gforge.ictp.it). RegCM4.5 is based on the NCAR MM5 mesoscale model with two dynamical cores: hydrostatic and nonhydrostatic (Giorgi et al. 2016). The hydrostatic core of the model has been extensively used to study the climate of East Asia and other regions with in general satisfactory simulation capability (Yang et al. 2018; Zhou et al. 2018; Juneng et al. 2016; Kong et al. 2019). Although the nonhydrostatic core allows for simulations at higher horizontal resolutions for the order of a few kilometers less than $15 \mathrm{~km}$ (Giorgi et al. 2016; Elguindi et al. 2014), the hydrostatic core is cheaper computationally and shows better performance of 

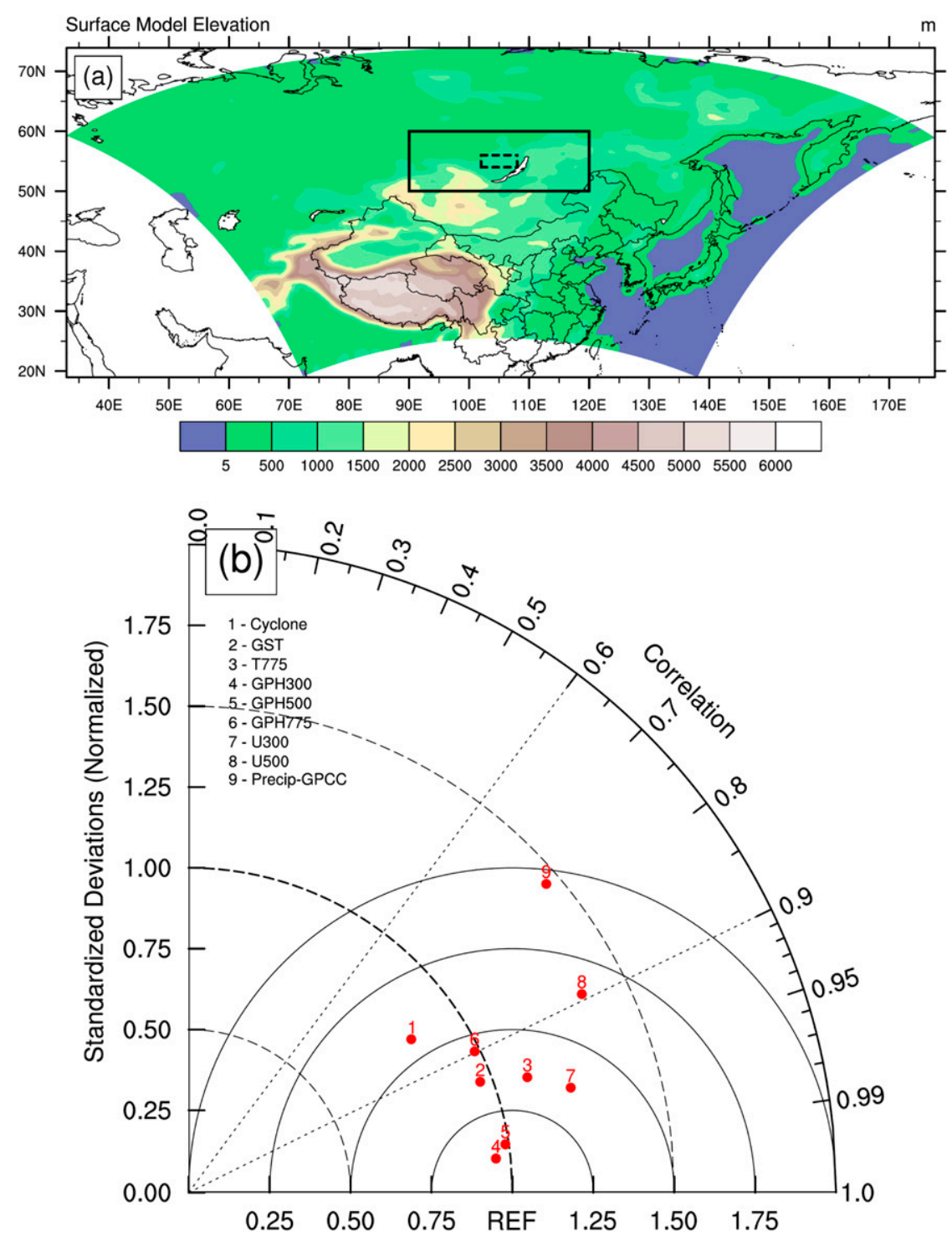

FIG. 3. (a) Topography in the model area (shaded; $\mathrm{m}$ ). The area surrounded by black solid line is the key GST region $\left(50^{\circ}-60^{\circ} \mathrm{N}, 90^{\circ}-120^{\circ} \mathrm{E}\right)$ for the experiments of $\mathrm{SH} \pm 20, \mathrm{SH} \pm 40$, and $\mathrm{SH} \pm 80$. The forcing was gradually diminished from the inner boundary (dashed line) to the outer boundary (solid line) of the key GST region. (b) Taylor diagram for pattern statistics of cyclogenesis, ground surface temperature (GST), air temperature at $775 \mathrm{hPa}$ (T775), geopotential height at 300, 500, and $775 \mathrm{hPa}$ (GPH300, GPH500, and GPH775), zonal wind at 300 and $500 \mathrm{hPa}$ (U300 and U500), and precipitation. The pattern statistics are calculated between the model results of CTL, ERA-Interim reanalysis, and GPCC data.

precipitation simulation in many recent studies (Adeniyi 2019; Pongracz et al. 2018). Considering the purpose of simulating the large-scale climate response and the computational cost, the hydrostatic dynamical core is used in the model dynamic framework. The model domain, which includes a large part of the middle latitudes of East Asia, is shown in Fig. 3a. Briefly, RegCM4.5 is configured with 1) the Lambert projection with the reference parallels at $30^{\circ}$ and $60^{\circ} \mathrm{N}, 2$ ) a resolution of $50 \mathrm{~km}$ in the horizontal, 3) 18 vertical sigma-levels, 4) the cumulus convection scheme of Emanuel (1991), and 5) the planetary boundary layer scheme of Holtslag et al. (1990). It is driven by the 6-hourly reanalysis of the NCEP-DOE and NOAA (National Oceanic and Atmospheric Administration) weekly Optimum Interpolation Sea Surface Temperature (OISST) analysis version 2 (Reynolds et al. 2002; https://www.esrl.noaa.gov/psd/) during 1 June to 31 August for the period of 1982-2017. The model results at 18 sigma levels are saved at 6-hourly interval and interpolated to 17 pressure levels for analysis. The main physical 
TABLE 1. The main physical process parameterization schemes and geolocation information used in the model configuration.

\begin{tabular}{lc}
\hline \hline \multicolumn{1}{c}{ Scheme } & Description \\
\hline Model dynamics & Hydrostatic \\
Cartographic projection & Lambert \\
Horizontal resolution & $50 \mathrm{~km}$ \\
Vertical levels & $18 \sigma$ levels \\
Central latitude/longitude & $50^{\circ} \mathrm{N}, 105^{\circ} \mathrm{E}$ \\
Number of grid points & $109 \times 144$ \\
Land surface model & $\mathrm{CLM} 4.5($ Oleson et al. 2013) \\
Cumulus convection & Emanuel (Emanuel 1991) \\
Planetary boundary layer & Holtslag (Holtslag et al. 1990) \\
\hline
\end{tabular}

process parameterization schemes and geolocation information used in the model configuration are summarized in Table 1.

In the present study, the Community Land Model (CLM) version 4.5, developed by the National Center for Atmospheric Research (Oleson et al. 2013), is used in the RegCM4.5 to represent land surface processes. Since GST is of great importance in the surface energy balance and can be affected by the sensible heat, we designed three groups of experiments during 1982-2017, without and with an anomalous forcing in the key GST region, in order to explore the effects of July GST anomalies. The first is the control run (CTL), which has no anomalous forcing applied in the key GST region. The next two are model sensitivity experiments with increases and decreases in sensible heat to emulate the land surface thermal anomalies. An anomalous forcing of up to $\pm 20, \pm 40$, and $\pm 80 \mathrm{~W} \mathrm{~m}^{-2}$ is added to the total sensible heat flux to the atmosphere over the key GST region at each time step in the model run of July in three subset experiments, which are referred to as $\mathrm{SH} \pm 20, \mathrm{SH} \pm 40$, and $\mathrm{SH} \pm$ 80 , respectively. The forcing is $\pm 20, \pm 40$, and $\pm 80 \mathrm{~W} \mathrm{~m}^{-2}$ over the central area $\left(54^{\circ}-56^{\circ} \mathrm{N}, 102^{\circ}-108^{\circ} \mathrm{E}\right.$, delineated by the dashed rectangle in Fig. 3a), gradually decreased outward, and reached $\pm 4, \pm 8$, and $\pm 16 \mathrm{~W} \mathrm{~m}^{-2}$ at the outermost areas within the key GST region. The regional average $\mathrm{SH}$ forcing added to the three subset experiments over the key GST region are about $\pm 9.05, \pm 18.10$, and $\pm 36.19 \mathrm{~W} \mathrm{~m}^{-2}$ in the experiments of $\mathrm{SH} \pm 20, \mathrm{SH} \pm 40$, and $\mathrm{SH} \pm 80$, respectively. After the forcing is added, the changed ground surface heat flux will affect the surface processes to maintain the energy balance and then adjust the GST, which can generally produce the observed land surface temperature anomalies. The magnitude of $\mathrm{SH}$ forcing applied is hypothetical but can highlight the impacts of GST anomalies and increase the signal-to-noise ratio, which is often small to biogeophysical effects of land surface disturbances in climate models. In each subset experiment, 36 runs are performed during 1982-2017, and every run is integrated from 1 June to 31 August in each year. The SH forcing is only added in July in each run of the sensitivity experiments, and the first month of the integration is considered as spinup.

The model results are interpolated into $1.5^{\circ} \times 1.5^{\circ}$ horizontal resolution. The subsets of the sensitivity experiments share the same boundary conditions for the period 1982-2017. All the anomalies of simulated variables in July are obtained by composing the differences between the sensitivity experiments $\mathrm{SH} \pm 20, \mathrm{SH} \pm 40$, and
$\mathrm{SH} \pm 80$. For example, the SH-20's cyclogenesis frequency is first subtracted from the results of $\mathrm{SH}+20$ to obtain the cyclone anomalies with a sample size of 36, and the average of the 36-yr differences is then calculated for analysis. Student's $t$ test with the null hypothesis that the average differences is zero is carried out to conduct the significant test with the 0.05 confidence level. A detailed discussion of results is presented in the following sections.

\section{c. Model evaluation}

The performance of the model to simulate EC activity, circulation, precipitation, and surface heat fluxes is evaluated by validating the CTL run against the ERA-Interim reanalysis and GPCC data during July (Fig. 3b). All the pattern statistics are calculated over the area of $25^{\circ}-73.5^{\circ} \mathrm{N}$ and $80^{\circ}-130^{\circ} \mathrm{E}$, which covers most of the middle latitudes of East Asia. The Taylor diagram in Fig. $3 \mathrm{~b}$ shows that the pattern correlations for GST, 775-hPa air temperature, geopotential height, and zonal wind are all greater than 0.9 , except the correlation of 0.89 for $500-\mathrm{hPa}$ horizontal wind and 0.76 for precipitation. The standard deviations of these variables in CTL are 0.951.45 times those of the ERA-Interim reanalysis and GPCC data. For EC activity, the pattern correlation of the cyclogenesis frequency is 0.82 and the ratio of standard deviation is 0.83 . Figure 4 further shows the spatial distribution of cyclogenesis frequency, precipitation, ground surface temperature, $500-\mathrm{hPa}$ geopotential height, 500-hPa temperature, and 200-hPa horizontal wind from the CTL and reanalysis. Evidently, the RegCM4.5 is able to realistically capture the spatial distribution of EC activity, such as the key EC region and a relatively weak cyclone activity center from the southeast coast of China to Japan, which is consistent with the previous studies and the main cyclogenesis location found by the manual identification (Ulbrich et al. 2009; Zhang 1984; Zhu et al. 2000; Wang et al. 2009; Zhang et al. 2012). The key EC region is related to the mean meridional temperature gradient and is consistent with the average position of the baroclinic frontal zone, which can be reflected by the dense isotherms shown in Figs. 4d, 4h, and 41. The key EC region is located in the eastern areas of the Mongolian Plateau, which is consistent with the study of Zhang et al. (2012) showing that leeward slope is another important reason for the high frequency of cyclone formation in the key EC region. However, compared to the results of ERA-Interim and NCEP-DOE, the model slightly underestimates the cyclogenesis frequency. In addition, the main rain belts and the decrease of summer precipitation from southeast to northwest are well simulated. The precipitation in northeastern China shown in Figs. 4b, 4f, and $4 \mathrm{j}$, is in correspondence with the eastward movement of cyclones from the key EC region to northeastern China (Chen et al. 2017b). The distribution of GST and the location of subtropical high are also well captured by the model. We further evaluated the temporal variation of GST and precipitation during July over the middle latitudes of East Asia, and the correlation coefficients is 0.73 for GST between CTL run and ERA-Interim, and 0.49 for precipitation between CTL and GPCC, which both pass the $t$ test at the 0.01 confidence level. Overall, the RegCM4.5 is generally able to realistically simulate the EC activity, circulation, and land surface temperatures. 

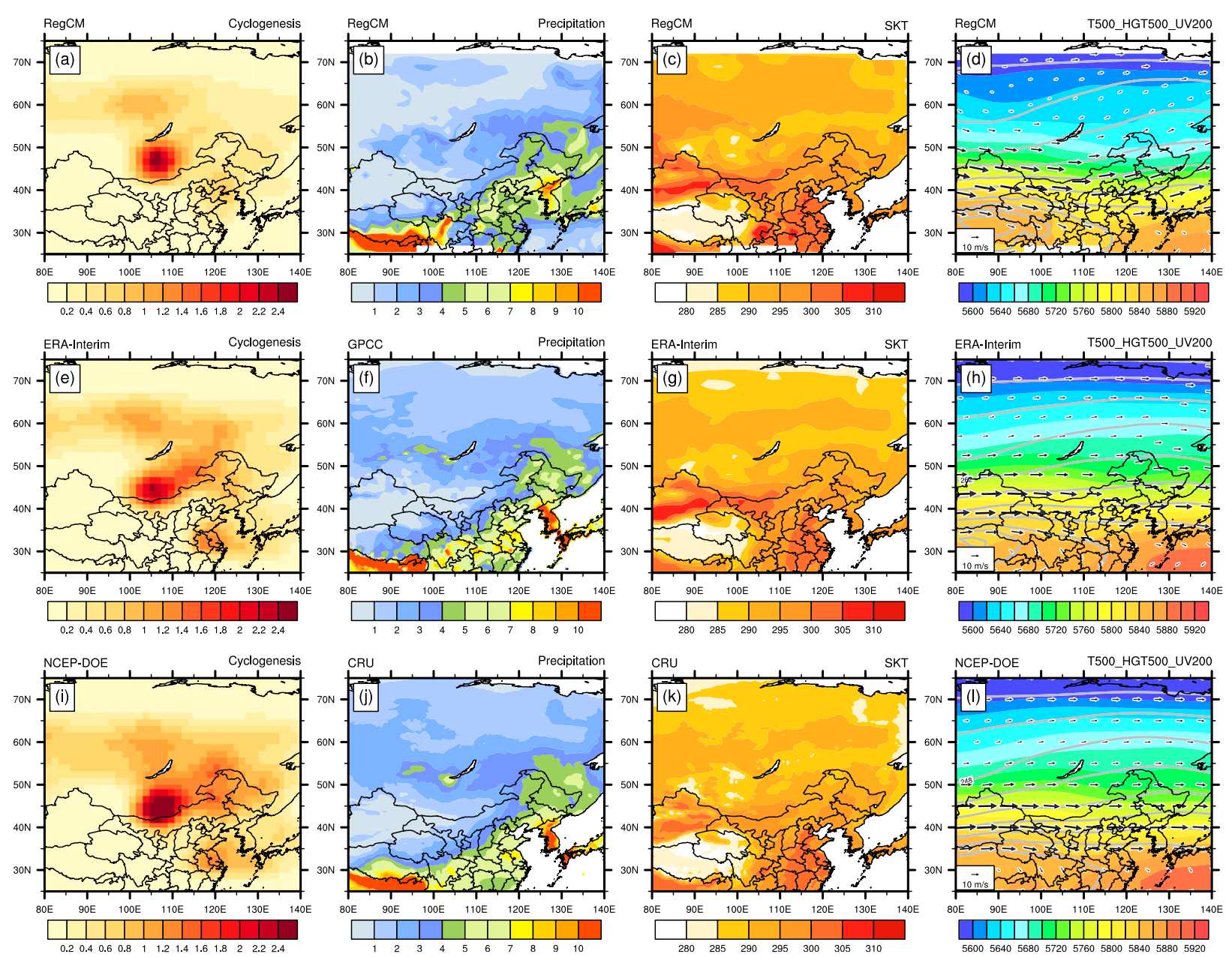

FIG. 4. Cyclogenesis frequency distribution of July for (a) CTL, (e) ERA-Interim, and (i) NCEP-DOE. Precipitation (mm day ${ }^{-1}$ ) distribution of July for (b) CTL, (f) GPCC, and (j) CRU. Ground surface temperature of July for (c) CTL, (g) ERA-Interim, and (k) CRU. The 500-hPa geopotential height (shaded; gpm), 500-hPa temperature (solid; K) and 200-hPa horizontal winds (vectors; $\mathrm{m} \mathrm{s}^{-1}$ ) of July for (d) CTL, (h) ERA-Interim, and (l) NCEP-DOE.

To examine the reasonability of the SH forcing added to the sensitivity experiments of $\mathrm{SH} \pm 20, \mathrm{SH} \pm 40$, and $\mathrm{SH} \pm 80$, we first obtain the regional average of GST in the key GST region before and after removing the linear trend, and then select the years with anomalous warming and cooling July GST, if exceeding one standard deviation of the regional average GST. The composite analysis of the GST difference between anomalous warming/cooling years and the climatology without removing the linear trend is shown in Figs. 5a and 5e (figures with the detrended data are not shown for brevity). Figures $5 \mathrm{~b}-\mathrm{d}$ and $5 \mathrm{f}-\mathrm{h}$ are the GST differences between the sensitivity experiments of $\mathrm{SH} \pm 20$, $\mathrm{SH} \pm 40, \mathrm{SH} \pm 80$, and CTL. In Fig. 5, the average GST anomalies over the key GST region are about $-4.75,-2.12,-1.16$, $1.18,1.75$, and $3.19 \mathrm{~K}$ in the experiments of $\mathrm{SH}-80, \mathrm{SH}-40$, $\mathrm{SH}-20, \mathrm{SH}+20, \mathrm{SH}+40$, and $\mathrm{SH}+80$, respectively. For the sensitivity experiments, the magnitudes of the GST anomalies in $\mathrm{SH} \pm 20, \mathrm{SH} \pm 40$, and $\mathrm{SH} \pm 80$ are generally comparable to the magnitudes in the reanalysis, indicating that the anomalous $\mathrm{SH}$ forcing added to the sensitivity experiments produces realistic GST anomalies.

\section{Results of sensitivity experiments}

\section{a. Cyclone anomalies}

To analyze the anomalous cyclone activity, the differences between the sensitivity experiments (i.e., $\mathrm{SH}+$ minus $\mathrm{SH}-$ ) are composed for the model results. Figure 6 shows the differences in cyclogenesis frequency and $775-\mathrm{hPa}$ maximum Eady growth rate between the sensitivity experiments with the positive and negative SH forcing over the key GST region. When the GST forcing over the key GST region is positive (negative) with any magnitude, the key EC region is a distinct center of negative (positive) anomaly, passing the $t$ test with the 0.05 confidence level, which is generally consistent with the results of MCA (Fig. 1). Moreover, as the warm (cold) GST forcing being 

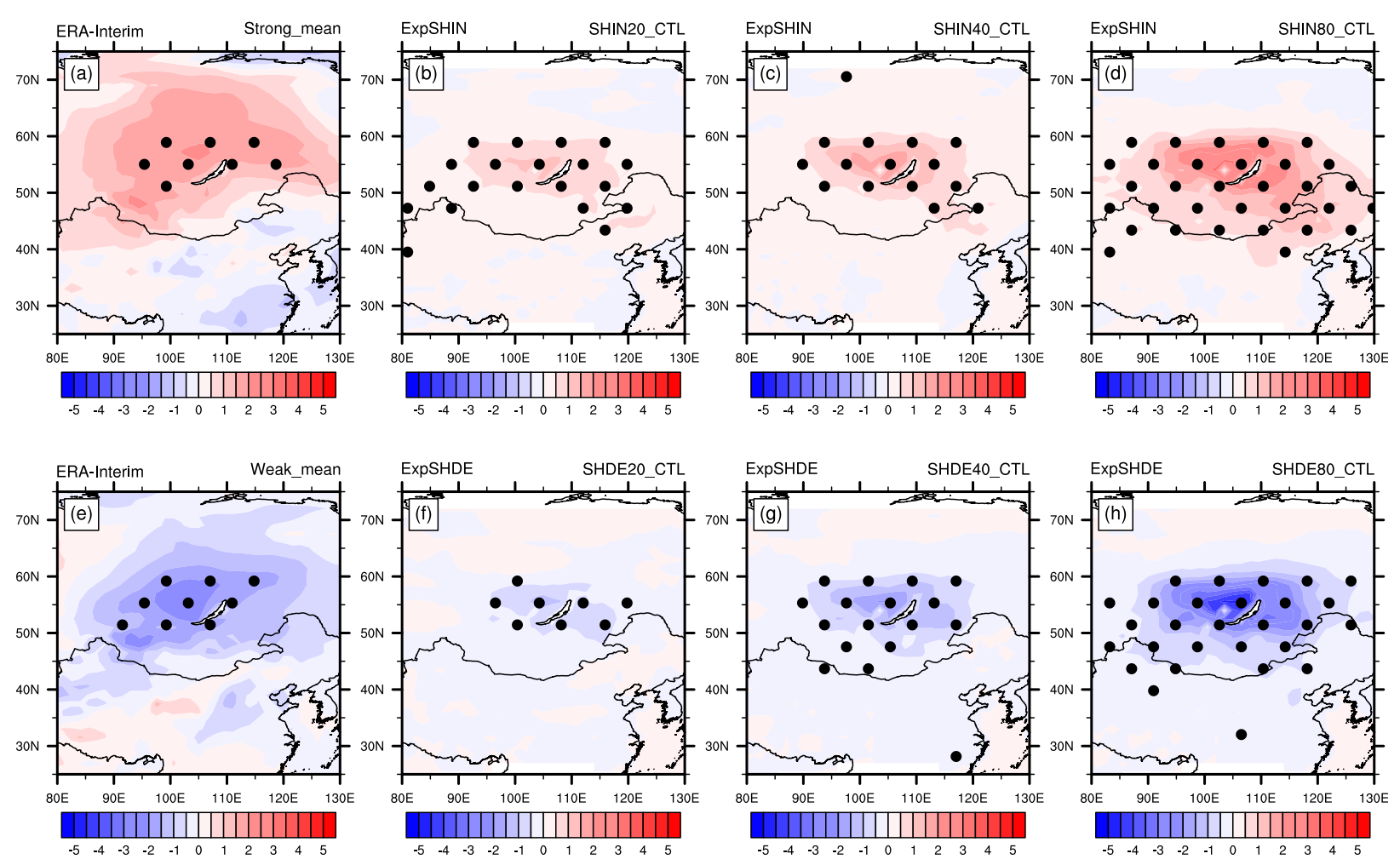

FIG. 5. Composite difference in July ground surface temperature (K) between anomalous (a) warming and (e) cooling years and the climatology. Also shown are differences in July ground surface temperature (K) between the sensitivity experiments (b) $-(\mathrm{d}) \mathrm{SH}+20$, $\mathrm{SH}+40$, and $\mathrm{SH}+80$ and (f)-(h) $\mathrm{SH}-20, \mathrm{SH}-40$, and SH -80 and the control run (CTL). The black dots indicate the anomalies are statistically significant at the 0.05 level.

increased (decreased) over the key GST region, cyclogenesis frequency declines (increases) over the key EC region.

To further explore the possible mechanism for the influence of GST anomaly on EC activity, we selected the maximum Eady growth rate at $775 \mathrm{hPa}, \sigma_{\mathrm{BI}}=0.31\left(\left|f U_{z}\right| / N\right)=0.31\left(\mathrm{M}^{2} / N\right)$ [where $f$ is the geostrophic parameter, $U_{z}$ is the vertical wind shear, $M$ is a measure of the meridional gradient of the potential temperature and can be estimated according to $M^{2}=$ $|-g(\partial \operatorname{In} \theta / \partial y)|$, and $N$ is the Brunt-Väisälä frequency and is defined by $\left.\left.N^{2}=g|\partial \operatorname{In} \theta / \partial z|\right)\right]$ to measure the intensity of the atmospheric baroclinicity for further analysis (Eady 1949; Lindzen et al. 1980). Since the equation of $\sigma_{\mathrm{BI}}$ is nonlinear, the mean $\sigma_{\mathrm{BI}}$ calculated from the time-mean data differs from that calculated from the averages of $\sigma_{\mathrm{BI}}$ calculated at synoptic scale, and the latter one is more appropriate that has been proved by Simmonds and Lim (2009). Here we used the daily data to calculate the maximum Eady growth rate. It is noted that the key EC region also exhibits the significant anomalous maximum Eady growth rate at $775 \mathrm{hPa}$, which is similar to the anomalous EC activity because the atmospheric baroclinicity is closely related to the activities of ECs and storm tracks.

The scatterplots in Fig. 7 show a general relationship between the anomalies of ECs and maximum Eady growth rate at $775 \mathrm{hPa}$ averaged in the key EC region against the GST anomalies over the key GST region. For both variables with increasing SH, the warm GST anomalies in the key GST region will lead to the decrease in both the EC activity and the atmospheric baroclinicity over the key EC region. The correlation coefficients between anomalous EC activity, maximum Eady growth rate at $775 \mathrm{hPa}$ in the key EC region and the GST anomalies in the key GST region are -0.34 and -0.67 , respectively. Both pass the $t$ test at the 0.05 confidence level. We further performed the above analysis for the warming trend slowdown period 2000-15, during which the GST leveled off. The ECs and maximum Eady growth rate at $775 \mathrm{hPa}$ exhibit similar spatial patterns to that of the whole study period 19822017 (figure not shown). These results indicate the negative correlation between atmospheric baroclinicity, cyclogenesis frequency and the ground surface temperature: The strong (weak) GST anomalies in the key GST region is always accompanied by a decrease (increase) in the atmospheric baroclinicity, and relatively weak (strong) cyclone activity in the key EC region. They are consistent with the previous findings in section 2, which supports our conclusion about the relationship between GST and EC activity over the midlatitude region of East Asia.

\section{b. Energy conversion anomalies}

To reveal the underlying mechanism responsible for the effect of the land surface thermal anomalies on the midlatitude EC activity, next we perform a diagnosis of the specific processes of the energy conversion based on the equations of eddy effective potential 

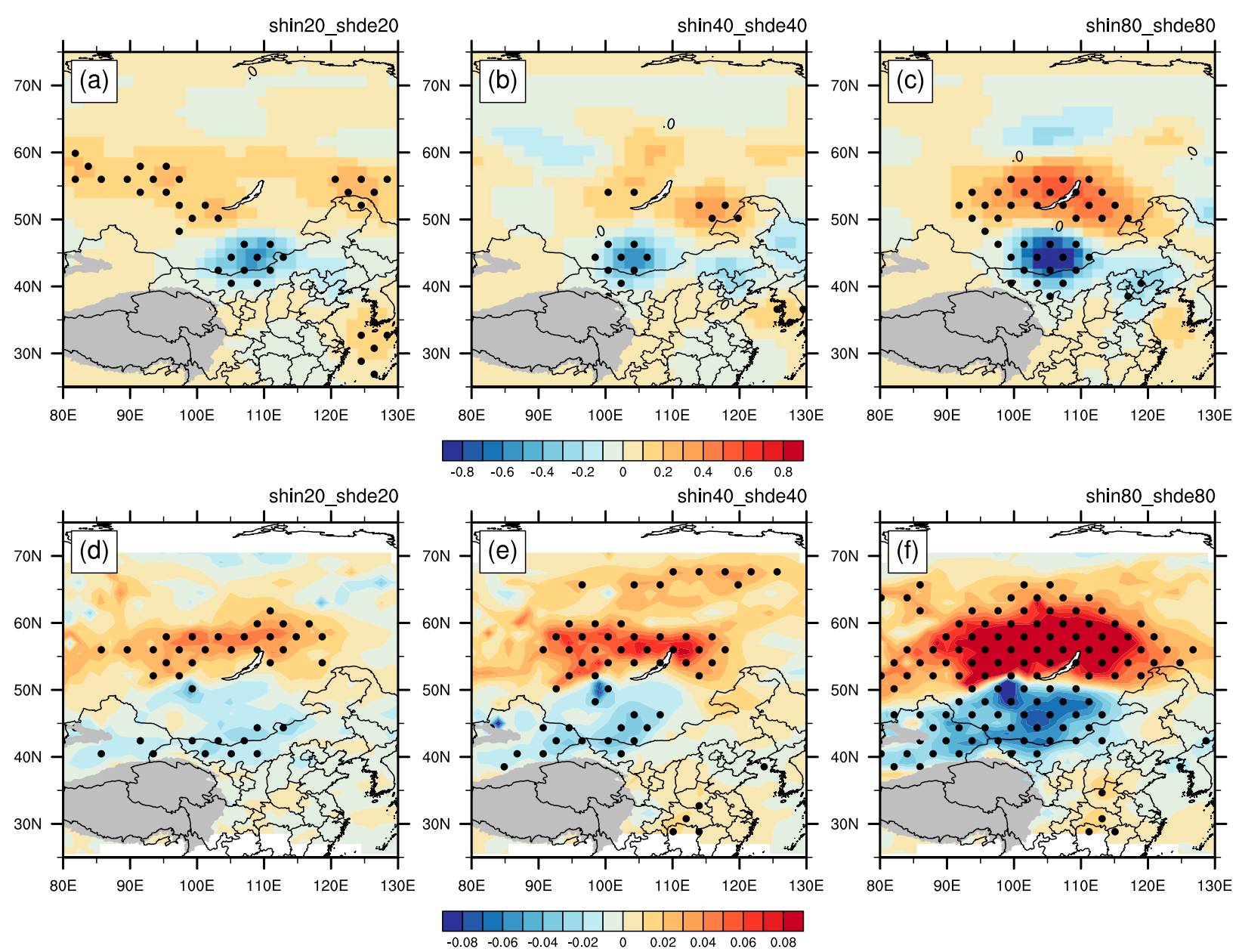

FIG. 6. Differences in (a)-(c) cyclogenesis frequency and (d)-(f) 775-hPa maximum Eady growth rate (day ${ }^{-1}$ ) of July between the experiments with the positive and negative SH forcing over the key GST region. Experiments with the magnitude of the SH forcing of (left) 20 , (center) 40 , and (right) $80 \mathrm{~W} \mathrm{~m}^{-2}$, i.e., $\mathrm{SH} \pm 20, \mathrm{SH} \pm 40$, and $\mathrm{SH} \pm 80$, respectively. The black dots indicate the anomalies are statistically significant at the 0.05 level.

energy and eddy kinetic energy (Orlanski and Katzfey 1991; Chang and Orlanski 1993). Here we mainly focused our analysis on the following four energy terms that related to the baroclinic conversion of the eddy energy budget (Chen et al. 2019): 1) eddy effective potential energy $\left.A_{e}=(1 / 2)\left[\left(T^{\prime}\right)^{2} / r\right], 2\right)$ eddy kinetic energy $K_{e}=$ $\left.(1 / 2)\left(u^{\prime 2}+v^{\prime 2}\right), 3\right)$ the baroclinic conversion between the timemean effective potential energy and eddy effective potential energy $I\left(A_{m}, A_{e}\right)=-(1 / r) \overline{T^{\prime} \cdot \mathbf{V}^{\prime}} \cdot \nabla \overline{T_{m}}$, and 4$)$ the baroclinic conversion between the eddy effective potential energy and the eddy kinetic energy $I\left(A_{e}, K_{e}\right)=-(R / P) \overline{\omega^{\prime} T^{\prime}}$. The meanings of the variables used in the energy terms are as follows: 1$) r=-\left(1 / \rho_{0}\right)\left(\partial \operatorname{In} \theta_{0} / \partial p\right)\left(p_{0} /\right.$ $R)^{2}$ is the static stability parameter, 2) $\rho_{0}$ and $\theta_{0}$ are the density and potential temperature at a reference surface, respectively, 3 ) $\mathbf{V}^{\prime}=u^{\prime} \mathbf{i}+v^{\prime} \mathbf{j}$ is the two-dimensional eddy horizontal wind vector; 4) $\mathbf{V}_{m}=u_{m} \mathbf{i}+v_{m} \mathbf{j}$ represents the time-mean horizontal wind vector, 5) $T^{\prime}$ is the eddy temperature, 6) $\varphi^{\prime}$ is the eddy portion of geopotential height, and 7) $\omega^{\prime}$ is the eddy vertical velocity. The detailed description of the formulations and meaning of the energy conversions here can be found in the references cited above. A case study on its application to a particular exceptional baroclinic storm propagating to Nome (Alaska) in October 1992 also provides a good example for understanding the energy conversion process (Pezza et al. 2010). Veiga et al. (2008) presented an analysis of the environmental energetics associated with the transition of the first South Atlantic hurricane, which advanced the understanding of the application and formulation of energy conversion analysis.

We derive the anomalous energy conversion terms in the model following the same method used to obtain the anomalous EC activity. Figure 8 presents the differences of anomalous $I\left(A_{m}, A_{e}\right), A_{e}, I\left(A_{e}, K_{e}\right)$, and $K_{e}$ at $775 \mathrm{hPa}$ for the experiments of $\mathrm{SH} \pm 20, \mathrm{SH} \pm 40$, and $\mathrm{SH} \pm 80$. Evidently, when the GST forcing anomaly over the key GST region is positive (negative), significant negative (positive) anomalies in the four energy conversion terms appears in the key EC region. The vertical sections of anomalous energy conversion terms between $90^{\circ}$ and $120^{\circ} \mathrm{E}$ are further examined in Fig. 9. In contrast to the warm (cold) GST forcing north of $50^{\circ} \mathrm{N}$, the energy 

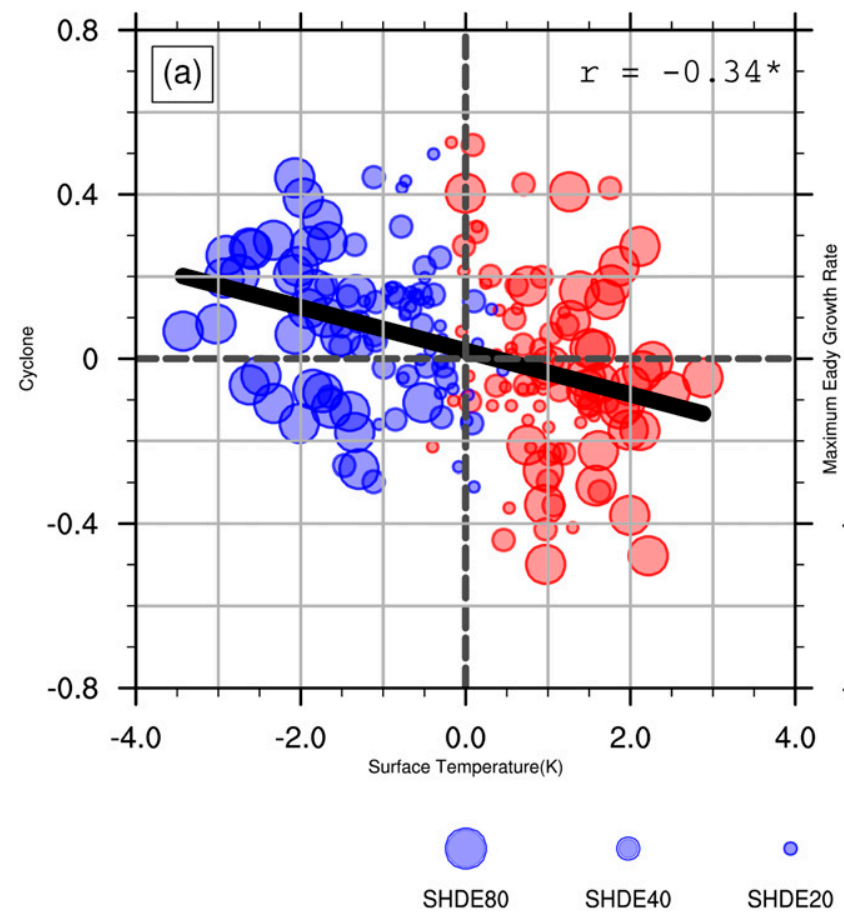
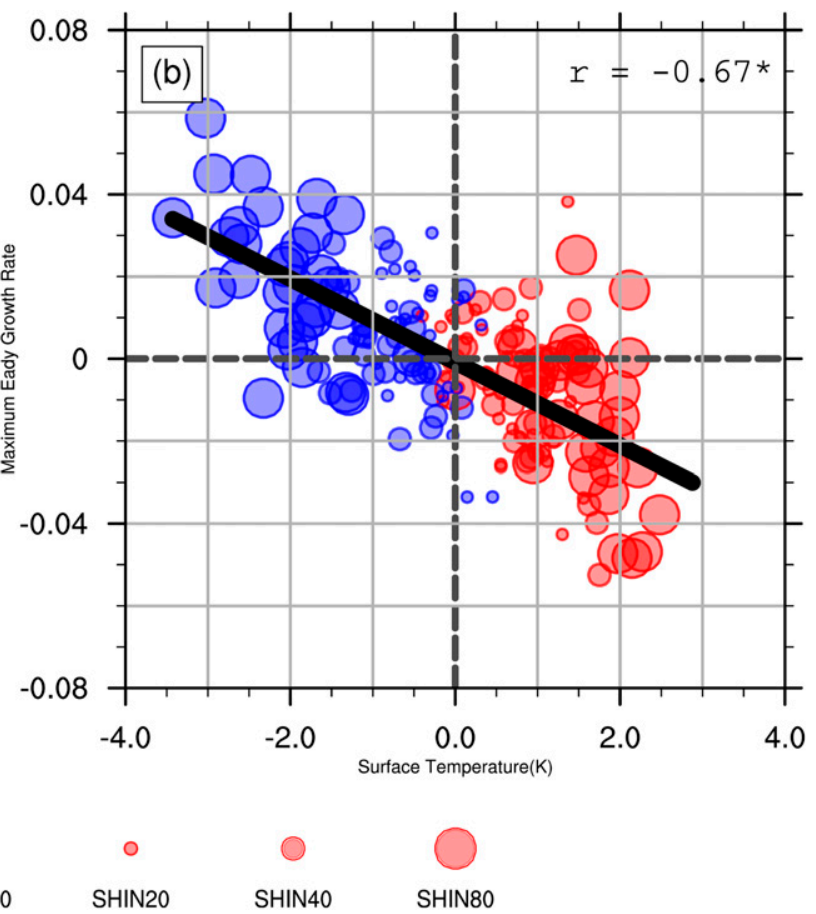

FIG. 7. Scatterplots of (a) anomalous cyclogenesis frequency ( $y$ axis) and (b) 775-hPa maximum Eady growth rate $\left(y\right.$ axis; day ${ }^{-1}$ ) of July over the key EC region $\left(40^{\circ}-50^{\circ} \mathrm{N}, 90^{\circ}-120^{\circ} \mathrm{E}\right)$ against the July ground surface temperature anomalies $(x$ axis; K) over the key GST region $\left(50^{\circ}-60^{\circ} \mathrm{N}, 90^{\circ}-120^{\circ} \mathrm{E}\right)$. The red (blue) filled circle in each plot represents the positive (negative) SH forcing. Moreover, the size of the circle corresponds to the magnitude of the SH forcing, just as shown by the legend at the bottom of the figure. The thick black line is the linear fit line with the regression coefficient shown in the upper right corner of the plot. The asterisk in the superscript of the coefficient suggests the regression passing $p=0.05$ significance test.

conversion terms exhibit a negative (positive) anomalous center between $40^{\circ}$ and $50^{\circ} \mathrm{N}$. The anomalous center of $I\left(A_{m}, A_{e}\right), A_{e}$, $I\left(A_{e}, K_{e}\right)$ are mainly located at $\sim 775 \mathrm{hPa}$ in the lower troposphere, which is consistent with the vertical distribution of atmospheric baroclinicity. When it comes to the eddy kinetic energy $K_{e}$, the significant anomalous center moves to the upper level at $\sim 300 \mathrm{hPa}$, which differs from other energy terms and is much stronger, possibly due to the interaction between synoptic eddy and low-frequency flow. The feedback between the two could amplify the eddy kinetic energy and their differences (Jin et al. 2006; Jin 2010), which needs future investigation.

To better understand the above relationships, we calculate the regional averaged anomalous GST, surface $\mathrm{SH}$ over the key GST region, and 775-hPa maximum Eady growth rate, cyclogenesis frequency, and the energy conversion terms over the key EC region for the sensitivity experiments of $\mathrm{SH} \pm 20, \mathrm{SH} \pm$ 40 , and $\mathrm{SH} \pm 80$, respectively. Figure 10 shows that, in general, the effects of GST over the key GST region increase with the magnitude of $\mathrm{SH}$ forcing added to the simulation. Positive (negative) GST anomalies over the key GST region decrease (increase) the $775-\mathrm{hPa}$ maximum Eady growth rate and the relevant energy conversion, producing the distinct negative (positive) anomaly of cyclone activity in the key EC region.

Therefore, we can infer that because the energy conversion terms are directly related to the atmospheric baroclinicity, the warm (cold) GST forcing over the key GST region weakens (enhances) the atmospheric baroclinicity via influencing the meridional gradient of temperature. The decreased (increased) $I\left(A_{m}, A_{e}\right)$ over the key EC region negatively (positively) contributes to the intensity of $A_{e}$, which further induces the decline (increase) of the baroclinic conversion term $I\left(A_{e}, K_{e}\right)$, and thereby alter the eddy kinetic energy $K_{e}$. These changes weaken (enhance) the conversion of energy from the time-mean flow to the synoptic-scale eddy and result in the negative (positive) anomalous EC activity.

\section{c. Atmospheric circulation and precipitation anomalies}

We further investigate the anomalous atmospheric circulation and precipitation linked with the EC activity anomalies in this section. Figure 11 presents the differences of anomalous 2-m air temperature and precipitation for the experiments of $\mathrm{SH} \pm 20, \mathrm{SH} \pm 40$, and $\mathrm{SH} \pm 80$, respectively. For the warm GST forcing over the key GST region, we find that 1) the air temperature over the Lake Baikal area gets warmer; 2) the precipitation generally shows a dipole pattern with significantly suppressed precipitation in northern and northeastern China, and enhanced rainfall south of $40^{\circ} \mathrm{N}$ of East Asia, mainly over the East China Sea (Figs. 11d-f); 3) Lake Baikal and its adjacent areas are occupied by a strong anticyclonic circulation while a relatively weak cyclonic circulation is located over the southeast coastal area of China, which is beneficial to decrease the precipitation in northern and northeastern China and 

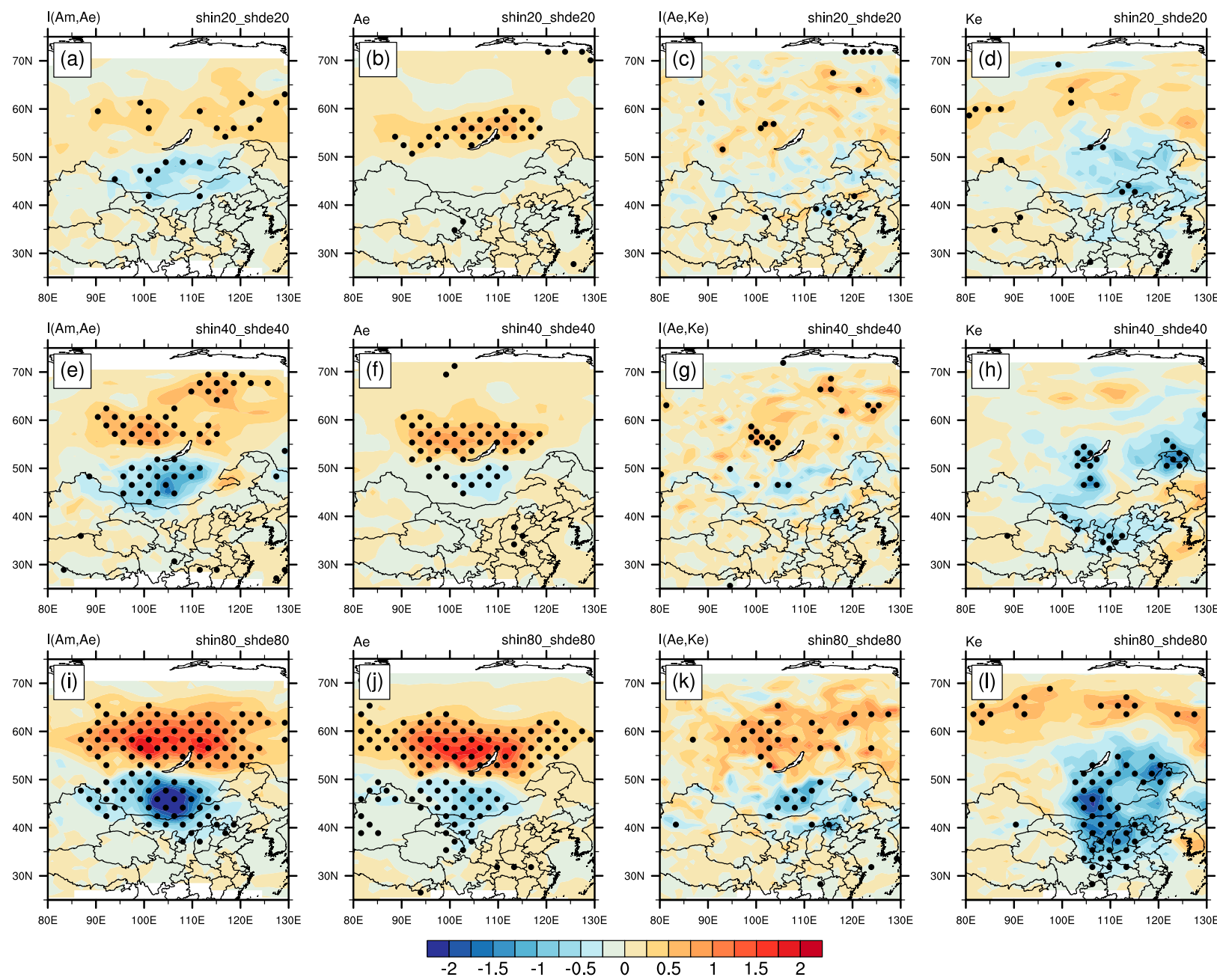

FIG. 8. Differences in (a),(e),(i) $I\left(A_{m}, A_{e}\right)\left(1 \times 10^{-4} \mathrm{~m}^{2} \mathrm{~s}^{-3}\right),(\mathrm{b}),(\mathrm{f}),(\mathrm{j}) A_{e}\left(\mathrm{~m}^{2} \mathrm{~s}^{-2}\right),(\mathrm{c}),(\mathrm{g}),(\mathrm{k}) I\left(A_{e}, K_{e}\right)\left(1 \times 10^{-4} \mathrm{~m}^{2} \mathrm{~s}^{-3}\right)$, and (d),(h),(l) $K_{e}\left(\mathrm{~m}^{2} \mathrm{~s}^{-2}\right)$ of July at $775 \mathrm{hPa}$ between the experiments of (top) $\mathrm{SH} \pm 20$, (middle) $\mathrm{SH} \pm 40$, and (bottom) $\mathrm{SH} \pm 80$. The black dots indicate the anomalies are statistically significant at the 0.05 level.

increase the precipitation over southern China to the East China Sea; and 4) there is an anomalous northeasterly wind to the southeast of the anticyclonic circulation, which is completely opposite to the atmospheric circulation anomalies that are associated with to the second mode of the EASM. The weakening of the southwesterly wind also provides an explanation for the reduction of precipitation in northern and northeastern China. The opposite situation occurred in the cases with the negative GST anomalies over the key GST region. Furthermore, Figs. 11g-i show the vertical integral of moisture flux and its divergence for the total column between the experiments of $\mathrm{SH} \pm 20, \mathrm{SH} \pm 40$, and $\mathrm{SH} \pm$ 80. Corresponding to the precipitation anomalies, the moisture flux is divergent in northern and northeastern China but convergent south of $40^{\circ} \mathrm{N}$ of East Asia, mainly over the East China Sea. In addition, it is noticed that the precipitation anomalies are much stronger in northern and northeastern China but are relatively weaker in the south of $40^{\circ} \mathrm{N}$ over East Asia. Although the anomalous precipitation over the south of $40^{\circ} \mathrm{N}$ of East Asia fails the significance test, this dipole pattern of precipitation anomalies is generally consistent with the composite analysis of observed precipitation anomalies between anomalous warming and cooling years (figure not shown for brevity). It also exhibits characteristics similar to the spatial pattern of precipitation anomalies associated with the second mode of the EASM (Huang et al. 2015; Chen et al. 2017b). The consistency of the model and the observation result proves that GST forcing does contribute to the precipitation and EASM to a certain extent, rather than that GST forcing over the key GST region dominates the phenomenon. To some extent, the current results are based on the conclusion of qualitative analysis. As for quantitative analysis, more rigorous and complex experiments should be designed, which will be the focus of our subsequent work. Besides, the regional differences in the intensity of precipitation anomalies may also result significantly from the anomalous EC activity caused by the land surface thermal anomalies (Chen et al. 2017a). The analysis above reveals close relationships among land surface thermal anomalies, midlatitude ECs, 

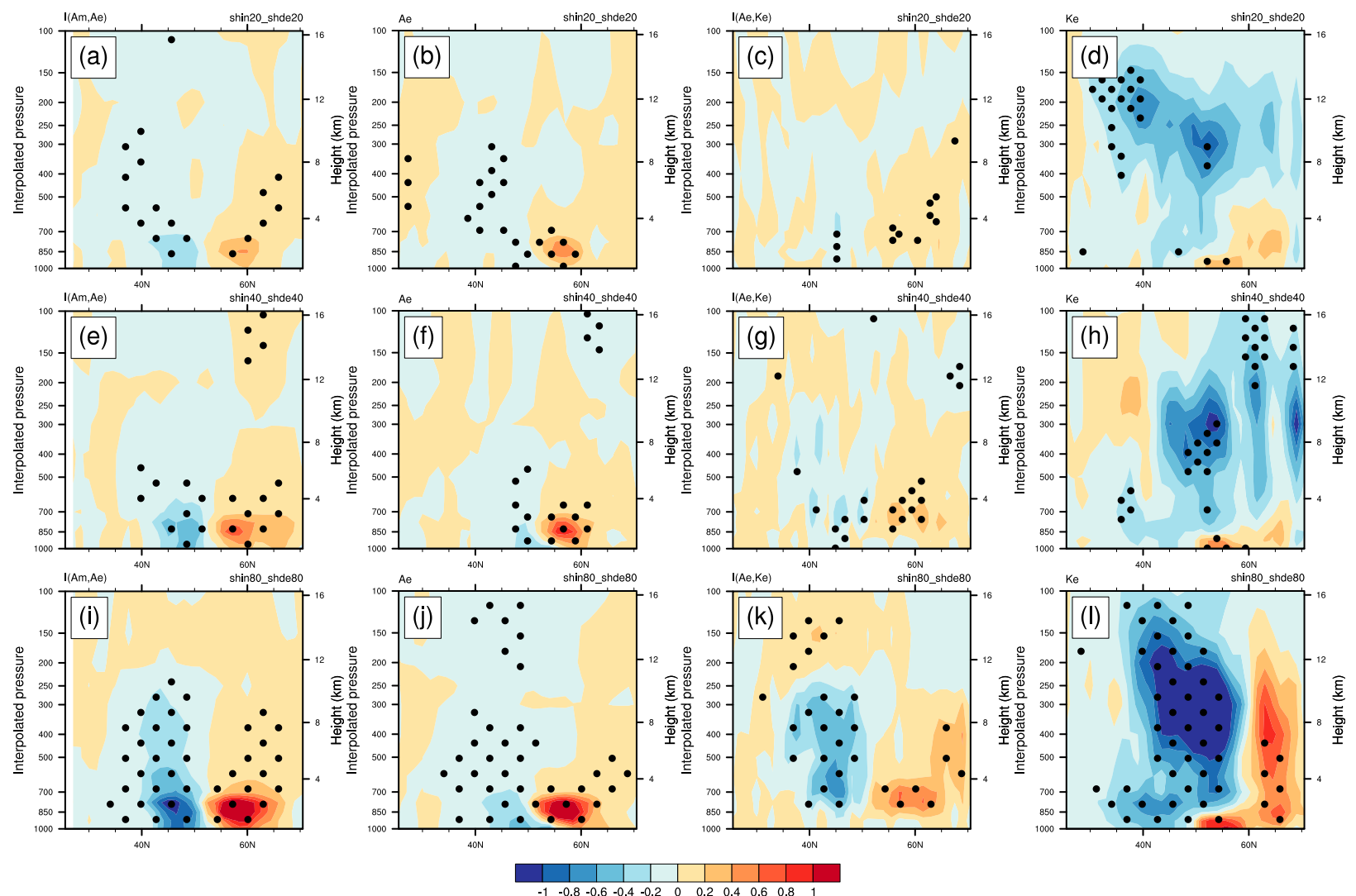

FIG. 9. Differences between the experiments of (top) $\mathrm{SH} \pm 20$, (middle) $\mathrm{SH} \pm 40$, and (bottom) $\mathrm{SH} \pm 80$ for the cross section of (a),(e),(i) $I\left(A_{m}, A_{e}\right)\left(1 \times 10^{-4} \mathrm{~m}^{2} \mathrm{~s}^{-3}\right),(\mathrm{b}),(\mathrm{f}),(\mathrm{j}) A_{e}\left(\mathrm{~m}^{2} \mathrm{~s}^{-2}\right),(\mathrm{c}),(\mathrm{g}),(\mathrm{k}) I\left(A_{e}, K_{e}\right)\left(1 \times 10^{-4} \mathrm{~m}^{2} \mathrm{~s}^{-3}\right)$, and (d), (h), (l) $K_{e}$ (m $\left.\mathrm{m}^{2} \mathrm{~s}^{-2}\right)$, of July at $775 \mathrm{hPa}$. The anomalies are averaged between $90^{\circ}$ and $120^{\circ} \mathrm{E}$. The black dots indicate the anomalies are statistically significant at the 0.05 level.

and EASM, which will be discussed with more detail at the end of this section, after analyzing the anomalous atmospheric circulation.

Besides the precipitation changes discussed above in Figs. 11d-f, it is noticed that when the GST forcing over the key GST region is warm (cold), the precipitation exhibits strong positive (negative) anomalies over the key GST region. These results, however, are inconsistent with observations, because minor positive precipitation anomalies are shown in the composite differences in the precipitation anomalies between anomalous warming and cooling years (figure not shown), which fails the significance test. Zhou et al. (2018) encountered the similar problem when verifying effects of the GST anomalies over the Tibetan Plateau on the
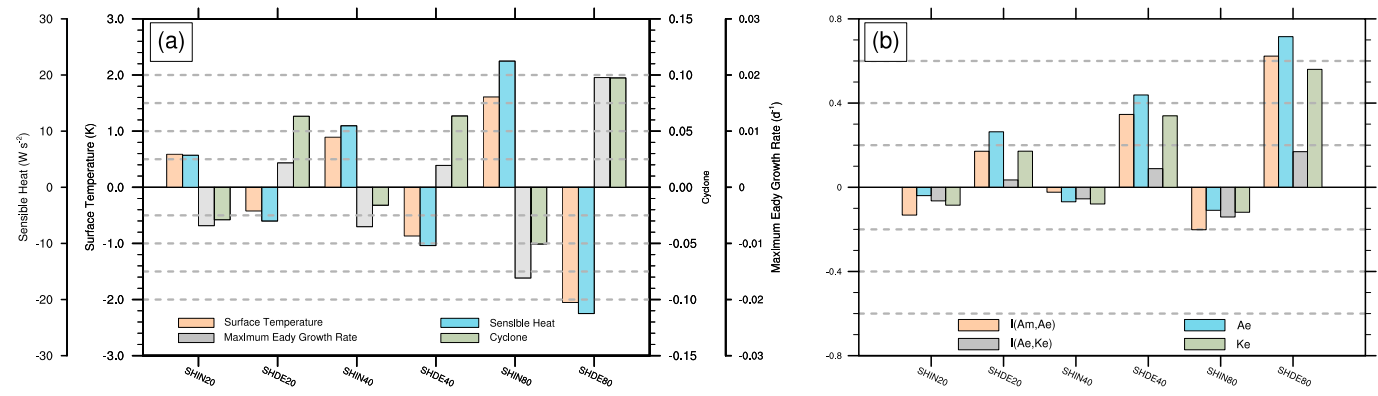

FIG. 10. (a) Ground surface temperature, surface sensible heat of July over the key GST region, and 775-hPa maximum Eady growth rate $\left(\right.$ day $\left.^{-1}\right)$, cyclogenesis frequency of July over the key EC region for sensitivity experiments of $\mathrm{SH} \pm 20, \mathrm{SH} \pm 40$, and $\mathrm{SH} \pm 80$. (b) $I\left(A_{m}, A_{e}\right)\left(1 \times 10^{-4} \mathrm{~m}^{2} \mathrm{~s}^{-3}\right), A_{e}\left(\mathrm{~m}^{2} \mathrm{~s}^{-2}\right), I\left(A_{e}, K_{e}\right)$ $\left(1 \times 10^{-4} \mathrm{~m}^{2} \mathrm{~s}^{-3}\right)$, and $K_{e}\left(\mathrm{~m}^{2} \mathrm{~s}^{-2}\right)$ of July at $775 \mathrm{hPa}$ over the key EC region for sensitivity experiments of $\mathrm{SH} \pm 20$, $\mathrm{SH} \pm 40$, and $\mathrm{SH} \pm 80$. 

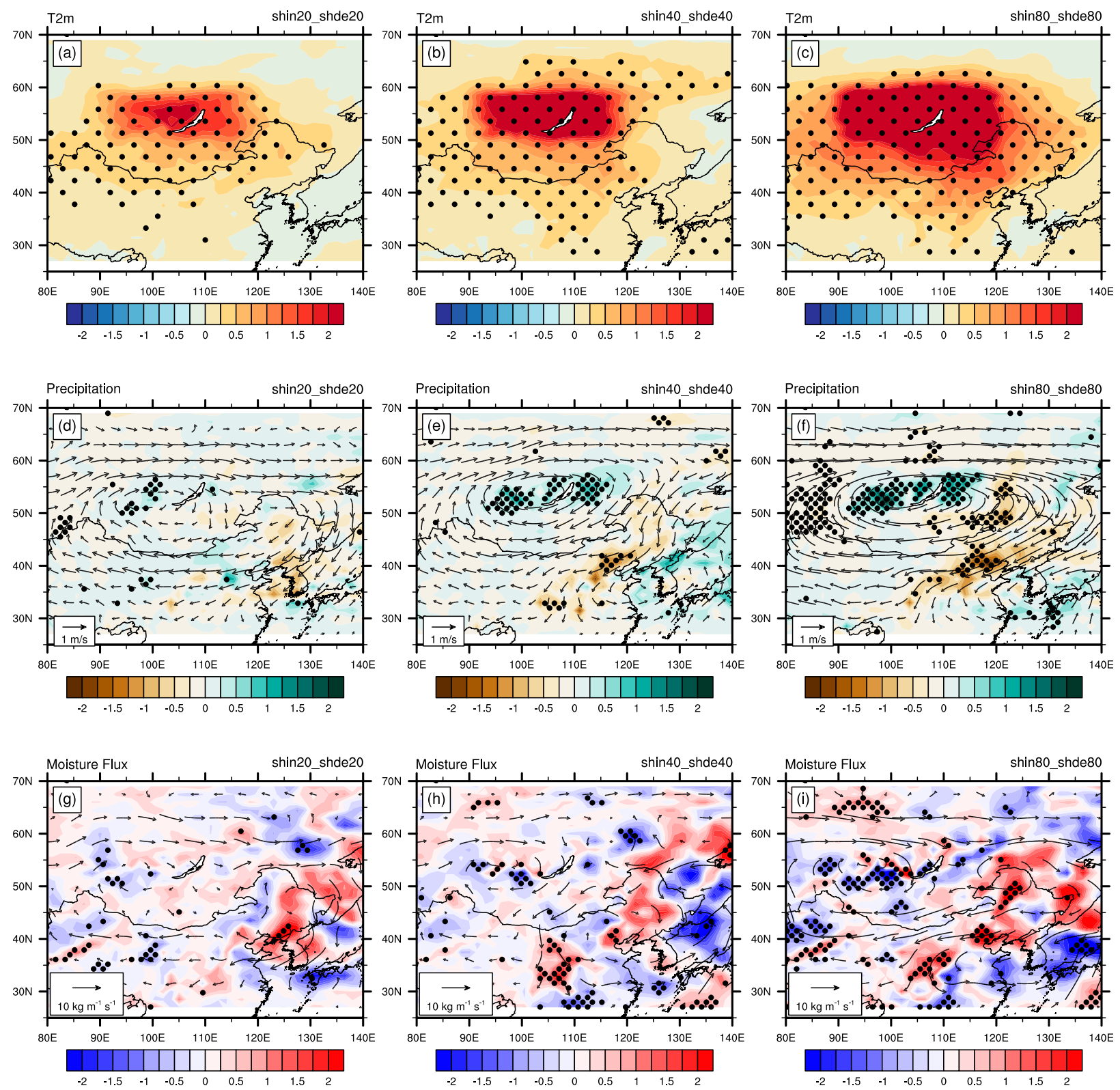

FIG. 11. Differences in (a)-(c) 2-m air temperature, (d)-(f) precipitation ( $\mathrm{mm} \mathrm{day}^{-1}$ ) and 500-hPa horizontal winds (vectors; $\mathrm{m} \mathrm{s}^{-1}$ ), and (g)-(i) vertical integral of moisture flux (vectors; $\mathrm{kg} \mathrm{m}^{-1} \mathrm{~s}^{-1}$ ) and its divergence (shaded; $10^{-5} \mathrm{~kg} \mathrm{~s}^{-1}$ ) for the total column of July between the experiments with the positive and negative SH forcing over the key GST region. Experiments with the magnitude of the SH forcing of (left) 20 , (center) 40 , and (right) $80 \mathrm{~W} \mathrm{~m}^{-2}$, i.e., $\mathrm{SH} \pm 20, \mathrm{SH} \pm 40$, and $\mathrm{SH} \pm 80$, respectively. The black dots indicate the anomalies are statistically significant at the 0.05 level.

rainfall over northwestern China and western Mongolia using the RegCM4.1. The reasons of the inconsistency between modeled and observed are that, in the model's sensitivity experiments, the anomalous precipitation over the key GST region is almost convective precipitation and is mainly driven by the anomalous forcing applied. However, for other regions over East Asia, these regions are dominated by large-scale precipitation and the spatial pattern of precipitation is consistent with the observations.
Compared to the influence of other factors on precipitation, the effects of GST anomalies in the sensitivity experiments are magnified and the resulting changes over the key GST region are much more intense than other areas simulated. When the GST forcing is warm in the model, it will cause upward movement and the moisture flux convergence over the key GST region (Figs. 11g-i), making the precipitation anomalies stronger than in reality over the key GST region. In observations, however, other factors 

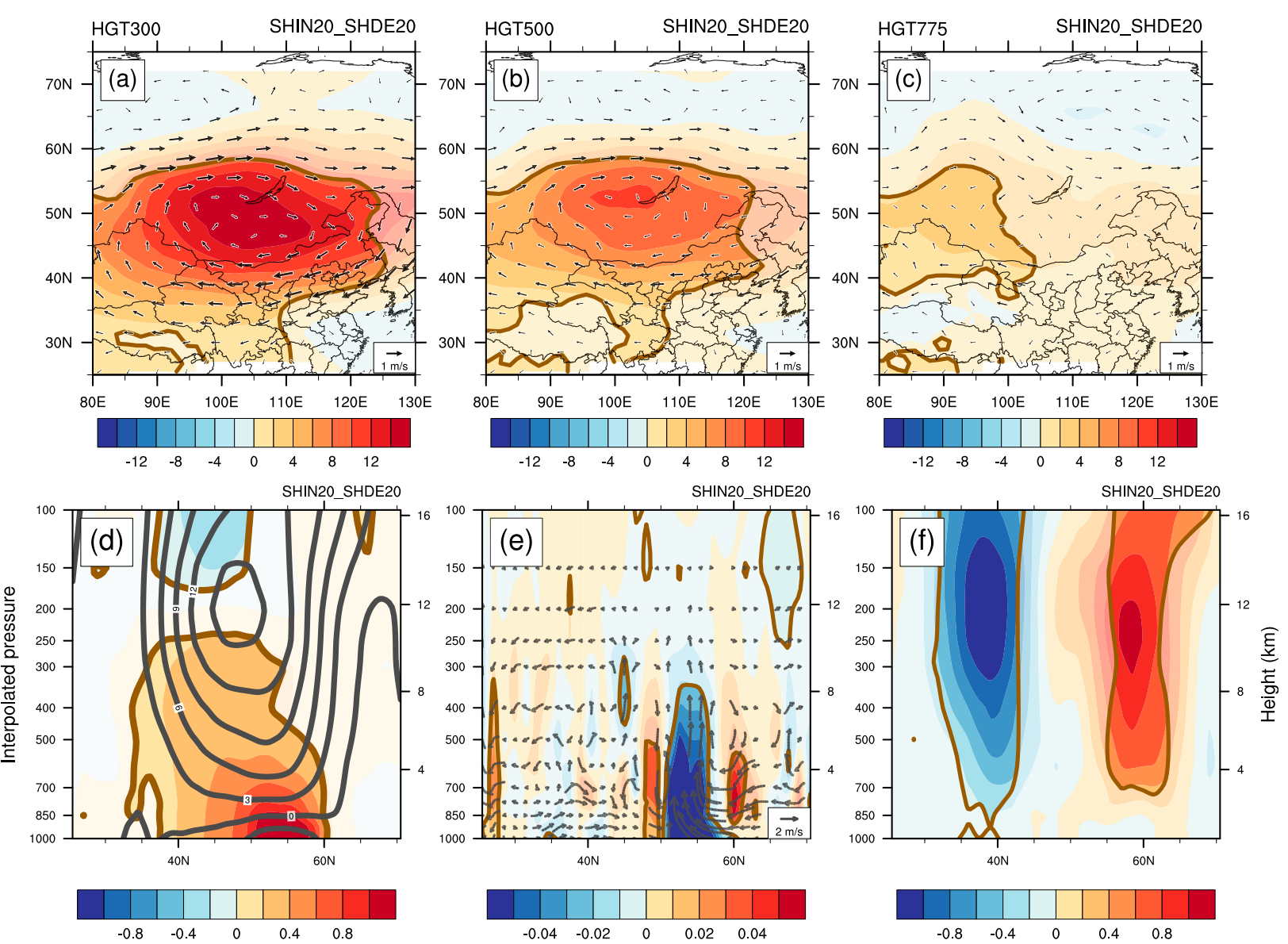

FIG. 12. Differences in geopotential height (shaded; $\mathrm{m}$ ), and horizontal winds (vectors; $\mathrm{m} \mathrm{s}^{-1}$ ) of July at (a) 300 , (b) 500 , and (c) $775 \mathrm{hPa}$ between the experiments of $\mathrm{SH} \pm 20$. (d) Anomalous air temperature (shaded, $\mathrm{K}$ ) and geopotential height (contours with the interval of $3 \mathrm{~m}$ ) of July between the experiments of $\mathrm{SH} \pm 20$. (e) Anomalous meridional circulation (vector with the vertical velocity multiplied by $10^{3}$ ) and vertical velocity (shaded; $10^{-3} \mathrm{~Pa} \mathrm{~s}^{-1}$ ) of July averaged along $90^{\circ}-120^{\circ} \mathrm{E}$. (f) Anomalous zonal wind ( $\mathrm{m} \mathrm{s}^{-1}$ ) of July averaged along $90^{\circ}-120^{\circ} \mathrm{E}$ between the experiments of $\mathrm{SH} \pm 20$. The thick brown lines in each figure denote regions with anomalous geopotential height in (a)-(c), air temperature in (d), vertical velocity in (e), and zonal wind in (f) that are statistically significant at the 0.05 level.

besides the GST forcing can significantly impact precipitation over the key GST region and thus suppress the effects of GST forcing on precipitation.

To further explore the atmospheric circulation anomalies, Figs. 12a-c depict the differences in the geopotential height anomaly at 300,500 , and $775 \mathrm{hPa}$ for the experiments of $\mathrm{SH} \pm$ 20. Evidently, when the GST forcing over the key GST region is warm (cold), there is a large area of negative (positive) geopotential height anomalies over the north of $60^{\circ} \mathrm{N}$ from the western Siberian Plain across the central Siberian Plain and extending to the Russian Far East. Meanwhile, the geopotential height anomaly field is positive (negative) over the midlatitude of East Asia $40^{\circ}-60^{\circ} \mathrm{N}$ at 775 and $500 \mathrm{hPa}$. At $300 \mathrm{hPa}$, the anomalous geopotential height is similar to 500 and $775 \mathrm{hPa}$ but stronger. Corresponding to the geopotential height anomalies, a strong anomalous anticyclonic (cyclonic) circulation pattern is centered over the south of Lake Baikal and exhibits consistent variations in the upper, middle, and lower troposphere, which show a quasi-barotropic structure. We can infer from the general circulation structure that the dynamic effect may play a dominant role.

The anomalous meridional geopotential height, air temperature, vertical circulation, vertical velocity, and zonal wind averaged from $90^{\circ}$ to $120^{\circ} \mathrm{E}$ are further examined in Figs. $12 \mathrm{~d}-\mathrm{f}$ for the experiments of $\mathrm{SH} \pm 20$. As shown in Fig. $12 \mathrm{~d}$ for $\mathrm{SH}+$ 20 ( $\mathrm{SH}-20$ ), a negative (positive) anomalous center of air temperature is above $200 \mathrm{hPa}$, and anomalous air temperature is positive (negative) below $250 \mathrm{hPa}$ over $40^{\circ}-60^{\circ} \mathrm{N}$. The troposphere exhibits a uniform positive (negative) anomaly from the bottom to the top with the positive (negative) anomalous center of geopotential height around $45^{\circ} \mathrm{N}$ at about $200 \mathrm{hPa}$, which is consistent with Figs. $12 \mathrm{a}-\mathrm{c}$. However, near the surface between $40^{\circ}$ and $60^{\circ} \mathrm{N}$, there are very shallow negative (positive) geopotential height anomalies. Figure 12e shows that descent (ascent) is over the south of $50^{\circ} \mathrm{N}$, and ascent (descent) is over the region between $50^{\circ}$ and $60^{\circ} \mathrm{N}$. The 

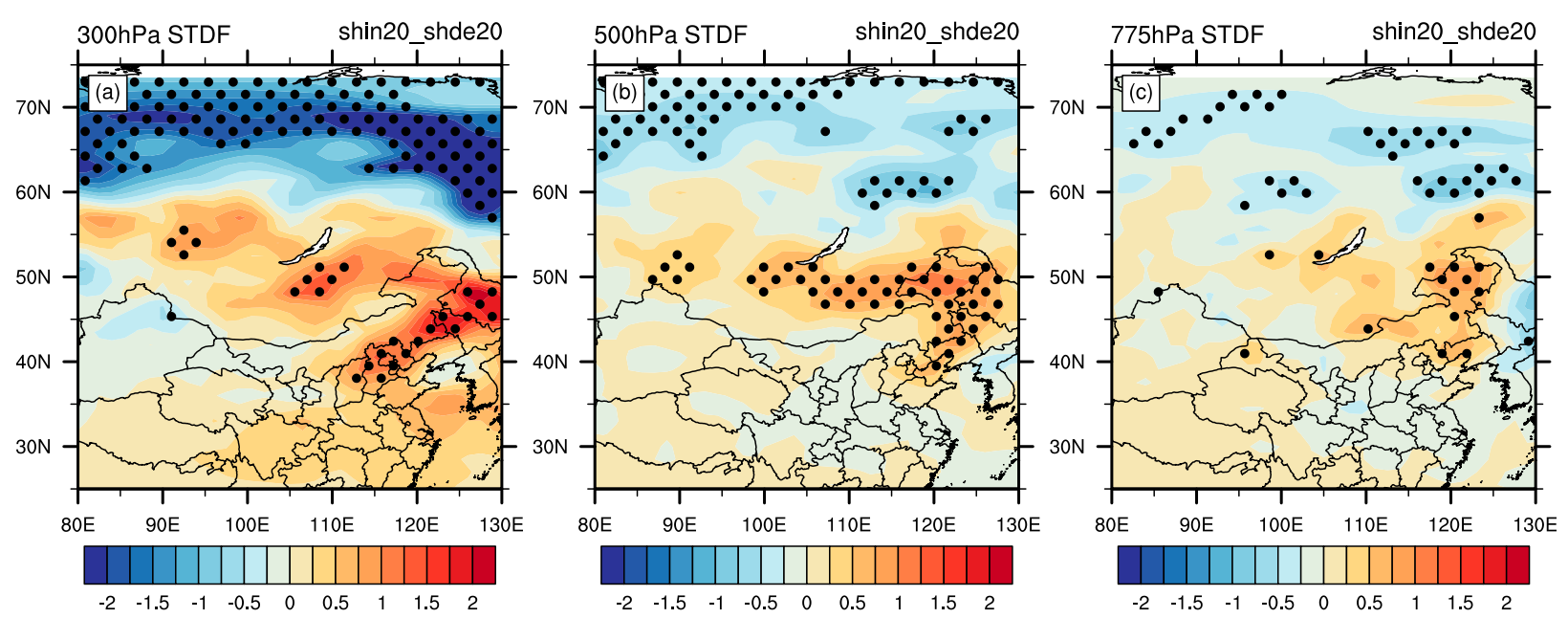

FIG. 13. Differences in the synoptic transient dynamic forcing (STDF; gpm day ${ }^{-1}$; shaded) of July at (a) 300 , (b) 500 , and (c) $775 \mathrm{hPa}$ between the experiments of $\mathrm{SH} \pm 20$. The black dots indicate the anomalies are statistically significant at the 0.05 level.

vertical velocity south of $50^{\circ} \mathrm{N}$ is significantly positive (negative), indicating a downward (upward) motion over this region unfavorable (favorable) to the eddy energy's baroclinic conversion. Additionally, the zonal wind is opposite in the north and south of $50^{\circ} \mathrm{N}$. Figure $12 \mathrm{f}$ indicates that, for the experiments of $\mathrm{SH} \pm 20$, the $60^{\circ} \mathrm{N}$ zonal wind is enhanced (weakened), which decreases (increases) the transport of highlatitude cold air to Lake Baikal. On the contrary, the zonal wind around $40^{\circ} \mathrm{N}$ is weakened (strengthened), which favors (disfavors) the transport of low-latitude warm air to the Baikal area. Therefore, the positive feedback between the GST forcing over the key GST region to the north of Lake Baikal and the atmospheric circulation makes contribution to the maintenance of the warm (cold) anomaly north of the Lake Baikal area, which is responsible for the negative (positive) EC anomalies over the key EC region and then further affects the EASM (more discussion in next section).

\section{d. Anomalies in transient wave activity and mean flow interaction}

The association of anomalous atmospheric circulation with the precipitation anomalies reveals some close connections among the land surface thermal anomalies, midlatitude cyclones, and the EASM. Considering the strong coupling between the cyclone frequency and storm tracks, the feedback of the synoptic-scale transient wave activity on the mean flow are proposed to explain the impact of the EC activity on the large-scale circulation associated with EASM. To diagnose the interaction between the transient wave activity and the time mean flow, we use the following terms: the synoptic transient dynamic forcing (STDF) on the mean flow expressed by the time averaged geopotential tendency, which has been used to diagnose the possible feedback of eddies on the intraseasonal variations of the East Asian trough (Song et al. 2016), and the horizontal Eliassen-Palm (EP) flux and its divergence (Trenberth 1986), which can be used to describe the interaction between the synoptic-scale wave and the lowfrequency flow in barotropic cases. The equations of these two terms are as follows: STDF $=-(f / g) \nabla_{h}^{-2}\left[\nabla_{h} \cdot \overline{\left(v^{\prime} \xi^{\prime}\right)}\right]$; $E_{u}=\left[(1 / 2)\left(v^{\prime 2}-u^{\prime 2}\right) \mathbf{i}, \overline{u^{\prime} v^{\prime}} \mathbf{j}\right] \times \cos \varphi$, where $u$ and $v$ are horizontal winds, $\xi$ is the vertical component of the vorticity, $f$ is the Coriolis parameter, $g$ is the gravitational acceleration, $h$ means the horizontal component, $\mathbf{i}$ and $\mathbf{j}$ represent the zonal and meridional unit vector, and $\varphi$ is the latitude. A Butterworth bandpass filter is used to obtain the synoptic-scale disturbance.

The STDF for the experiments of $\mathrm{SH} \pm 20$ in Figs. 13a-c shows that the positive (negative) GST anomalies in the key GST region will lead to the positive (negative) STDF anomalies over the midlatitude of East Asia, especially in the region between eastern Mongolia to the south of Lake Baikal and northeast China, which is a signal of the positive (negative) dynamic contribution of the synoptic-scale transient wave to the geopotential tendency. This positive (negative) anomaly distribution of STDF will suppress (enhance) the development of the East Asia trough. The large area of positive STDF anomaly is very similar to the distribution of positive geopotential anomalies and the location of anticyclone circulation, indicating a close linkage between the synoptic-scale transient wave activity and the strong positive anomaly of the geopotential height around Lake Baikal. The differences in EP flux and EP flux divergence between the experiments of $\mathrm{SH} \pm$ 20 support the same conclusion, that accompanied with the warm (cold) GST forcing, there is a negative (positive) anomaly of the EP flux divergence, which will suppress (enhance) of the conversion from the energy of the synoptic-scale disturbance to the kinetic energy of mean flow.

The analysis above demonstrates that the negative (positive) anomalous EC activity due to anomalous warm (cold) GST forcing over the key GST region south of the Lake Baikal will result in positive (negative) anomalies of the geopotential field over the Lake Baikal by the positive (negative) STDF anomaly, and at the same time weaken (enhance) the East Asia trough. The increase (decrease) of the positive (negative) dynamic contribution of the synoptic-scale transient wave to the geopotential tendency and the decrease (increase) of the 
energy conversion from the synoptic-scale disturbance to the mean flow are unfavorable (beneficial) to the development of the EASM.

\section{Conclusions and discussion}

Based on analyses of observational and reanalysis data and modeling experiments, this study, along with our previous research (Chen et al. 2017b, 2019), suggests a possible mechanism by which the land surface thermal anomaly affects the midlatitude extratropical cyclone activity and finally makes contribution to the East Asian summer monsoon anomalies. It is found that the land surface warming near $50^{\circ} \mathrm{N}$ and north to Lake Baikal may contribute to the weakening of the EC activity. This negative relationship between the July ground surface temperature over the key GST region $\left(50^{\circ}-60^{\circ} \mathrm{N}, 90^{\circ}-\right.$ $\left.120^{\circ} \mathrm{E}\right)$ and the cyclone activity over the key EC region $\left(40^{\circ}-\right.$ $50^{\circ} \mathrm{N}, 90^{\circ}-120^{\circ} \mathrm{E}$ ) exists before and after removing the linear trends, and is confirmed by both of our MCA analysis and numerical experiments. To determine the effects of the GST anomalies over the key GST region on midlatitude EC activity and the EASM, two groups of sensitivity experiments with positive and negative $\mathrm{SH}$ forcing added over the key GST region are conducted by RegCM4.5, as well as one set of control experiment. Through analyzing the anomalous cyclogenesis frequency in the sensitivity experiments, it is found that warming (cooling) land surface over the north of $50^{\circ} \mathrm{N}$ is always accompanied by a decrease (an increase) in the atmospheric baroclinicity in the key EC region. Since the energy conversion terms is directly related to the atmospheric baroclinicity, further analysis indicates that, when positive (negative) land surface warming appears over the key GST region, it will weaken (enhance) the conversion of energy from the timemean flow to the synoptic-scale eddy and result in the negative (positive) anomalous of the extratropical cyclogenesis and relatively weaker (stronger) EC activity.

We also examine the monsoon atmospheric circulation and precipitation associated with the negative relationship between the July ground surface temperature and the EC activity. The differences between sensitivity experiments shows that, when the GST forcing over the key GST region is abnormally warm (cold), the precipitation generally shows a dipole pattern with significantly suppressed (enhanced) precipitation in northern and northeastern China, and enhanced (suppressed) rainfall south of $40^{\circ} \mathrm{N}$ of East Asia, mainly over the East China Sea. Meanwhile, Lake Baikal and its adjacent areas are occupied by a strong anticyclonic (cyclonic) circulation and exhibits consistent variations in the upper, middle, and lower troposphere. And there is an anomalous northeasterly (southwesterly) wind to the southeast of the anticyclonic (cyclonic) circulation, which is completely opposite to (similar with) the atmospheric circulation anomalies that are associated with the second mode of the EASM. The weakening (strengthening) of the southwesterly wind also provides an explanation for the reduction (increment) of precipitation in northern and northeastern China. Descent (ascent) is over the south of $50^{\circ} \mathrm{N}$, and ascent (descent) is over the region between $50^{\circ}$ and $60^{\circ} \mathrm{N}$, respectively. The zonal wind also shows an opposite structure over the north and south of $50^{\circ} \mathrm{N}$. The $60^{\circ} \mathrm{N}$ zonal wind is enhanced (weakened), and the zonal wind around $40^{\circ} \mathrm{N}$ is weakened (strengthened). Therefore, the positive feedback between the GST forcing over the key GST region to the north of Lake Baikal and the atmospheric circulation makes contribution to the maintenance of the warm (cold) anomaly north of the Lake Baikal area, which is responsible for the negative (positive) EC anomalies over the key EC region. The negative (positive) anomalous EC activity due to anomalous warmer (colder) GST forcing over the key GST region south of the Lake Baikal will result in positive (negative) anomalies of the geopotential field over the Lake Baikal by the positive (negative) STDF anomaly. The increase (decrease) of the positive (negative) dynamic contribution of the synoptic-scale transient wave to the geopotential tendency and the decrease (increase) of the energy conversion from the synoptic scale disturbance to the mean flow are unfavorable (beneficial) to the development of the EASM.

In summary, this study first identifies the impacts of nonuniform land surface warming on summer anomalous extratropical cyclone activity and East Asian summer monsoon, and then explores the physical processes and mechanisms of how the anomalous GST forcing impacts on EC activity and monsoon circulation by numerical experiments with a regional climate model. However, the dynamic processes of the atmosphere are comprised of numerous complex processes and interactions and no model can ever be expected to simulate these processes without uncertainties (e.g., Foley 2010). Although the RegCM4.5 with the hydrostatic core is able to realistically capture the main characteristic of cyclogenesis frequency, precipitation, ground surface temperature and other processes, the nonhydrostatic core with higher horizontal resolutions may provide more reliable climate information on regional to local scales (Prein et al. 2015), and this may be an uncertainty that should be examined in the future. Furthermore, the GST anomalies over the midlatitude of East Asia may result from several factors. For example, the amplified nonuniform land surface warming over the Eurasian continent since the mid-1990s coincided with the start of the rapid decrease of summer Arctic sea ice (Simmonds 2015). The impact of Arctic sea ice loss on Eurasian temperature and circulation is now becoming well established by many studies and may be one of the possible key forcing that influences the GST anomalies (Yao et al. 2017; B. Luo et al. 2019; D. Luo et al. 2019). Besides the anomalies in Arctic sea ice, Pacific sea surface temperature, and snow cover/depth over northern Eurasia in winter and spring may also play an important role. Luo et al. (2017) demonstrate that the Atlantic multidecadal oscillation (AMO) also has a noticeable influence of the Eurasian surface air temperature anomalies. Therefore, our proposed feedback contribution of the synoptic-scale transient wave activity on the mean flow and the cause-and-effect chain we inferred from the thermal anomaly over the key GST region of Eurasia to the anomalies of cyclone activity, atmospheric circulation and climate over East Asia/East Asian summer monsoon (EASM) remains an open question that requires further investigation.

Acknowledgments. This study has been jointly supported by NSFC (41625019 and 42021004) and NUIST-UoR International Research Institute Research Fund. (The ERAInterim dataset is available at http://apps.ecmwf.int/datasets/, 
the NCEP-NCAR Reanalysis 1 data, NCEP Reanalysis 2 data, and NOAA OISST V2 data are available at https://www.esrl. noaa.gov/psd/, the GPCC datasets are available at https:// www.dwd.de/EN/ourservices/gpcc/gpcc.html, the CRU datasets are available at http://www.cru.uea.ac.uk/data/, and the MERRA-2 and GLDAS-1 data are available at https://disc.gsfc. nasa.gov/.)

\section{REFERENCES}

Adeniyi, M. O., 2019: Sensitivity of two dynamical cores in RegCM4.7 to the 2012 intense rainfall events over West Africa with focus on Lau, Nigeria. Int. J. Modell. Simul., 40, 355-365, https://doi.org/10.1080/02286203.2019.1641777.

Chang, E. K., and I. Orlanski, 1993: On the dynamics of a storm track. J. Atmos. Sci., 50, 999-1015, https://doi.org/10.1175/15200469(1993)050<0999:OTDOAS > 2.0.CO;2.

Chen, H., F. Teng, and D. Jiang, 2017a: Characteristics of East Asian midlatitude extra-tropical cyclone activity in spring and summer during 1979-2013 and its linkage with concurrent rainfall in Northeast China (in Chinese). Trans. Atmos. Sci., 40, 443-452, https://doi.org/ 10.13878/j.cnki.dqkxxb.20160322001.

,-- W. Zhang, and H. Liao, 2017b: Impacts of anomalous midlatitude cyclone activity over East Asia during summer on the decadal mode of East Asian summer monsoon and its possible mechanism. J. Climate, 30, 739-753, https://doi.org/ 10.1175/JCLI-D-16-0155.1.

—, W. Zhang, B. Zhou, F. Teng, J. Zhang, and Y. Zhou, 2019: Impact of nonuniform land surface warming on summer anomalous extratropical cyclone activity over East Asia. J. Geophys. Res. Atmos., 124, 10 306-10 320, https://doi.org/ 10.1029/2018JD030165.

—, B. Yu, B. Zhou, W. Zhang, and J. Zhang, 2020: Role of local atmospheric forcing and land-atmosphere interaction in recent land surface warming in the midlatitudes over East Asia. J. Climate, 33, 2295-2309, https://doi.org/10.1175/JCLI-D-180856.1 .

Chen, W., and R. Lu, 2014: A decadal shift of summer surface air temperature over Northeast Asia around the mid-1990s. $A d v$. Atmos. Sci., 31, 735-742, https://doi.org/10.1007/s00376-0133154-4.

— , and Coauthors, 2016: Variation in summer surface air temperature over northeast Asia and its associated circulation anomalies. Adv. Atmos. Sci., 33 (1), 1-9, https://doi.org/ 10.1007/s00376-015-5056-0.

Dash, S., P. Parth Sarthi, and S. Panda, 2006: A study on the effect of Eurasian snow on the summer monsoon circulation and rainfall using a spectral GCM. Int. J. Climatol., 26, 1017-1025, https://doi.org/10.1002/joc.1299.

Dee, D. P., and Coauthors, 2011: The ERA-Interim reanalysis: Configuration and performance of the data assimilation system. Quart. J. Roy. Meteor. Soc., 137, 553-597, https://doi.org/ 10.1002/qj.828.

Dong, B., and P. J. Valdes, 1998: Modelling the Asian summer monsoon rainfall and Eurasian winter/spring snow mass. Quart. J. Roy. Meteor. Soc., 124, 2567-2596, https://doi.org/ 10.1002/qj.49712455203.

, R. T. Sutton, W. Chen, X. Liu, R. Lu, and Y. Sun, 2016: Abrupt summer warming and changes in temperature extremes over Northeast Asia since the mid-1990s: Drivers and physical processes. Adv. Atmos. Sci., 33, 1005-1023, https:// doi.org/10.1007/s00376-016-5247-3.
,-- , and L. Shaffrey, 2017: Understanding the rapid summer warming and changes in temperature extremes since the mid1990s over western Europe. Climate Dyn., 48, 1537-1554, https://doi.org/10.1007/s00382-016-3158-8.

Eady, E. T., 1949: Long waves and cyclone waves. Tellus, 1, 33-52, https://doi.org/10.3402/tellusa.v1i3.8507.

Elguindi, N., and Coauthors, 2014: Regional climate model RegCM: Reference manual version 4.5. Abdus Salam ICTP, 33 pp.

Emanuel, K. A., 1991: A scheme for representing cumulus convection in large-scale models. J. Atmos. Sci., 48, 2313-2329, https://doi.org/10.1175/1520-0469(1991)048<2313:ASFRCC > 2.0.CO;2.

Foley, A., 2010: Uncertainty in regional climate modelling: A review. Prog. Phys. Geogr., 34, 647-670, https://doi.org/10.1177/ 0309133310375654.

Gelaro, R., and Coauthors, 2017: The Modern-Era Retrospective Analysis for Research and Applications, version 2 (MERRA-2). J. Climate, 30, 5419-5454, https://doi.org/10.1175/JCLI-D-16-0758.1.

Giorgi, F., F. Solmon, and G. Giuliani, 2016: Regional Climatic Model RegCM User's Guide, version 4.5. Abdus Salam ICTP, $59 \mathrm{pp}$.

Gulev, S., O. Zolina, and S. Grigoriev, 2001: Extratropical cyclone variability in the Northern Hemisphere winter from the NCEP/NCAR reanalysis data. Climate Dyn., 17, 795-809, https://doi.org/10.1007/s003820000145.

Han, Z., F. Luo, S. Li, Y. Gao, T. Furevik, and L. Svendsen, 2016: Simulation by CMIP5 models of the Atlantic multidecadal oscillation and its climate impacts. Adv. Atmos. Sci., 33, 13291342, https://doi.org/10.1007/s00376-016-5270-4.

Hansen, J., M. Sato, R. Ruedy, K. Lo, D. W. Lea, and M. MedinaElizade, 2006: Global temperature change. Proc. Natl. Acad. Sci. USA, 103, 14288-14293, https://doi.org/10.1073/pnas.0606291103.

—_, R. Ruedy, M. Sato, and K. Lo, 2010: Global surface temperature change. Rev. Geophys., 48, RG4004, https://doi.org/ 10.1029/2010RG000345.

Harris, I., P. D. Jones, T. J. Osborn, and D. H. Lister, 2014: Updated high-resolution grids of monthly climatic observations-The CRU TS3. 10 dataset. Int. J. Climatol., 34, 623-642, https:// doi.org/10.1002/joc.3711.

Holtslag, A., E. De Bruijn, and H. Pan, 1990: A high resolution air mass transformation model for short-range weather forecasting. Mon. Wea. Rev., 118, 1561-1575, https://doi.org/10.1175/ 1520-0493(1990)118<1561:AHRAMT>2.0.CO;2.

Hong, X., R. Lu, and S. Li, 2017: Amplified summer warming in Europe-west Asia and northeast Asia after the mid-1990s. Environ. Res. Lett., 12, 094007, https://doi.org/10.1088/17489326/aa7909.

Hoskins, B. J., and P. J. Valdes, 1990: On the existence of stormtracks. J. Atmos. Sci., 47, 1854-1864, https://doi.org/10.1175/ 1520-0469(1990)047<1854:OTEOST>2.0.CO;2.

Huang, Y., H. Chen, W. Jiang, B. Xu, and Z. Li, 2015: Multi-spatial modes of East Asian summer monsoon activity: Comparative analysis of various reanalysis data (in Chinese). Chin. J. Atmos. Sci., 39, 145-160, https://doi.org/10.3878/j.issn.10069895.1404.13326.

Jin, F., 2010: Eddy-induced instability for low-frequency variability. J. Atmos. Sci., 67, 1947-1964, https://doi.org/10.1175/ 2009JAS3185.1.

_ - L. Pan, and M. Watanabe, 2006: Dynamics of synoptic eddy and low-frequency flow interaction. Part I: A linear closure. J. Atmos. Sci., 63, 1677-1694, https://doi.org/10.1175/JAS3715.1.

Juneng, L., and Coauthors, 2016: Sensitivity of Southeast Asia rainfall simulations to cumulus and air-sea flux parameterizations in 
RegCM4. Climate Res., 69, 59-77, https://doi.org/10.3354/ cr01386.

Kalnay, E., and Coauthors, 1996: The NCEP/NCAR 40-Year Reanalysis Project. Bull. Amer. Meteor. Soc., 77, 437-471, https://doi.org/10.1175/1520-0477(1996)077<0437:TNYRP> 2.0.CO;2.

Kanamitsu, M., W. Ebisuzaki, J. Woollen, S.-K. Yang, J. J. Hnilo, M. Fiorino, and G. L. Potter, 2002: NCEP-DOE AMIP-II Reanalysis (R-2). Bull. Amer. Meteor. Soc., 83, 1631-1643, https://doi.org/10.1175/BAMS-83-11-1631.

Kong, X., A. Wang, X. Bi, and D. Wang, 2019: Assessment of temperature extremes in China using RegCM4 and WRF. Adv. Atmos. Sci., 36, 363-377, https://doi.org/10.1007/s00376-018-8144-0.

Lim, E.-P., and I. Simmonds, 2002: Explosive cyclone development in the Southern Hemisphere and a comparison with Northern Hemisphere events. Mon. Wea. Rev., 130, 21882209, https://doi.org/10.1175/1520-0493(2002)130<2188: ECDITS > 2.0.CO;2.

$\longrightarrow$, and — 2007: Southern Hemisphere winter extratropical cyclone characteristics and vertical organization observed with the ERA-40 data in 1979-2001. J. Climate, 20, 2675-2690, https://doi.org/10.1175/JCLI4135.1.

Lin, X.-Z., C.-F. Li, Z.-D. Lin, and R.-Y. Lu, 2018: Close relationship between the East Asian westerly jet and Russian Far East surface air temperature in summer. Atmos. Ocean. Sci. Lett., 11, 282-286, https://doi.org/10.1080/16742834.2018.1467726.

Lindzen, R. S., B. Farrell, and K.-K. Tung, 1980: The concept of wave overreflection and its application to baroclinic instability. J. Atmos. Sci., 37, 44-63, https://doi.org/10.1175/1520-0469(1980) 037<0044:TCOWOA $>2.0 . \mathrm{CO} ; 2$.

Luo, B., L. Wu, D. Luo, A. Dai, and I. Simmonds, 2019: The winter midlatitude-Arctic interaction: Effects of North Atlantic SST and high-latitude blocking on Arctic sea ice and Eurasian cooling. Climate Dyn., 52, 2981-3004, https://doi.org/10.1007/ s00382-018-4301-5.

Luo, D., Y. Chen, A. Dai, M. Mu, R. Zhang, and S. Ian, 2017: Winter Eurasian cooling linked with the Atlantic multidecadal oscillation. Environ. Res. Lett., 12, 125002, https://doi.org/ 10.1088/1748-9326/aa8de8.

— , X. Chen, J. Overland, I. Simmonds, Y. Wu, and P. Zhang, 2019: Weakened potential vorticity barrier linked to recent winter Arctic sea ice loss and midlatitude cold extremes. J. Climate, 32, 4235-4261, https://doi.org/10.1175/JCLI-D-18-0449.1.

McCabe, G. J., M. P. Clark, and M. C. Serreze, 2001: Trends in Northern Hemisphere surface cyclone frequency and intensity. J. Climate, 14, 2763-2768, https://doi.org/10.1175/15200442(2001)014<2763:TINHSC $>2.0$. CO;2.

Murray, R. J., and I. Simmonds, 1991a: A numerical scheme for tracking cyclone centres from digital data. Part II: Application to January and July general circulation model simulations. Aust. Meteor. Mag., 39, 167-180.

$\longrightarrow$, and — 1991b: A numerical scheme for tracking cyclone centres from digital data. Part I: Development and operation of the scheme. Aust. Meteor. Mag., 39, 155-166.

Oleson, K. W., and Coauthors, 2013: Technical description of version 4.5 of the Community Land Model (CLM). NCAR Tech. Note NCAR/TN-503+STR, 420 pp., https://doi.org/ 10.5065/D6RR1W7M.

Orlanski, I., and J. Katzfey, 1991: The life cycle of a cyclone wave in the Southern Hemisphere. Part I: Eddy energy budget. J. Atmos. Sci., 48, 1972-1998, https://doi.org/10.1175/15200469(1991)048<1972:TLCOAC > 2.0.CO;2.
Pezza, A. B., J. A. P. Veiga, I. Simmonds, K. Keay, and M. S. Mesquita, 2010: Environmental energetics of an exceptional high-latitude storm. Atmos. Sci. Lett., 11, 39-45, https:// doi.org/10.1002/asl.253.

- , H. A. Rashid, and I. Simmonds, 2012: Climate links and recent extremes in Antarctic sea ice, high-latitude cyclones, southern annular mode and ENSO. Climate Dyn., 38, 57-73, https://doi.org/10.1007/s00382-011-1044-y.

Pongracz, R., T. Kalmar, I. Pieczka, and J. Bartholy, 2018: Regional climate model validation for central/eastern Europe using hydrostatic vs non-hydrostatic approaches. 31st Conference on Climate Variability and Change, Austin, TX, Amer. Meteor. Soc., 553, https://ams.confex.com/ams/98Annual/webprogram/ Paper331261.html.

Prein, A. F., and Coauthors, 2015: A review on regional convectionpermitting climate modeling: Demonstrations, prospects, and challenges. Rev. Geophys., 53, 323-361, https://doi.org/10.1002/ 2014RG000475.

Reynolds, R. W., N. A. Rayner, T. M. Smith, D. C. Stokes, and W. Wang, 2002: An improved in situ and satellite SST analysis for climate. J. Climate, 15, 1609-1625, https://doi.org/10.1175/ 1520-0442(2002)015<1609:AIISAS > 2.0.CO;2.

Rodell, M., and Coauthors, 2004: The Global Land Data Assimilation System. Bull. Amer. Meteor. Soc., 85, 381-394, https://doi.org/ 10.1175/BAMS-85-3-381.

Rudeva, I., and I. Simmonds, 2015: Variability and trends of global atmospheric frontal activity and links with large-scale modes of variability. J. Climate, 28, 3311-3330, https://doi.org/10.1175/ JCLI-D-14-00458.1.

Schneider, U., A. Becker, P. Finger, A. Meyer-Christoffer, and M. Ziese, 2018: GPCC full data monthly product version 2018 at $0.25^{\circ}$ : Monthly land-surface precipitation from rain-gauges built on GTS-based and historical data. Accessed 15 November 2019, https://doi.org/10.5676/DWD_GPCC/FD_M_ V2018_025.

Simmonds, I., 2015: Comparing and contrasting the behaviour of Arctic and Antarctic sea ice over the 35 year period 1979-2013. Ann. Glaciol., 56, 18-28, https://doi.org/10.3189/2015AoG69A909.

— methods with data from FROST. Aust. Meteor. Mag., 35-49.

, and E. P. Lim, 2009: Biases in the calculation of Southern Hemisphere mean baroclinic eddy growth rate. Geophys. Res. Lett., 36, L01707, https://doi.org/10.1029/2008GL036320.

Simmons, A. J., and B. J. Hoskins, 1978: The life cycles of some nonlinear baroclinic waves. J. Atmos. Sci., 35, 414-432, https:// doi.org/10.1175/1520-0469(1978)035<0414:TLCOSN >2.0. $\mathrm{CO} ; 2$.

Song, L., L. Wang, W. Chen, and Y. Zhang, 2016: Intraseasonal variation of the strength of the East Asian trough and its climatic impacts in boreal winter. J. Climate, 29, 2557-2577, https://doi.org/10.1175/JCLI-D-14-00834.1.

Stainforth, D. A., S. C. Chapman, and N. W. Watkins, 2013: Mapping climate change in European temperature distributions. Environ. Res. Lett., 8, 034031, https://doi.org/10.1088/ 1748-9326/8/3/034031.

Sutton, R. T., and B. Dong, 2012: Atlantic Ocean influence on a shift in European climate in the 1990s. Nat. Geosci., 5, 788792, https://doi.org/10.1038/ngeo1595.

Trenberth, K. E., 1986: An assessment of the impact of transient eddies on the zonal flow during a blocking episode using localized EliassenPalm flux diagnostics. J. Atmos. Sci., 43, 2070-2087, https://doi.org/ 10.1175/1520-0469(1986)043<2070:AAOTIO>2.0.CO;2. 
Ulbrich, U., G. Leckebusch, and J. G. Pinto, 2009: Extra-tropical cyclones in the present and future climate: A review. Theor. Appl. Climatol., 96, 117-131, https://doi.org/10.1007/s00704008-0083-8.

Veiga, J. A. P., A. B. Pezza, I. Simmonds, and P. L. Silva Dias, 2008: An analysis of the environmental energetics associated with the transition of the first South Atlantic hurricane. Geophys. Res. Lett., 35, L15806, https://doi.org/10.1029/2008GL034511.

Vernekar, A., J. Zhou, and J. Shukla, 1995: The effect of Eurasian snow cover on the Indian monsoon. J. Climate, 8, 248-266, https://doi.org/10.1175/1520-0442(1995)008<0248:TEOESC $>$ 2.0.CO;2.

Wang, X., P. Zhai, and C. Wang, 2009: Variations in extratropical cyclone activity in northern East Asia. Adv. Atmos. Sci., 26, 471-479, https://doi.org/10.1007/s00376-009-0471-8.

Wang, X. L., V. R. Swail, and F. W. Zwiers, 2006: Climatology and changes of extratropical cyclone activity: Comparison of ERA40 with NCEP-NCAR reanalysis for 1958-2001. J. Climate, 19, 3145-3166, https://doi.org/10.1175/JCLI3781.1.

Wu, R., Z. Wen, S. Yang, and Y. Li, 2010: An interdecadal change in southern China summer rainfall around 1992/93. J. Climate, 23, 2389-2403, https://doi.org/10.1175/2009JCLI3336.1.

Yan, Y., C. Li, and R. Lu, 2019: Meridional displacement of the East Asian upper-tropospheric westerly jet and its relationship with the East Asian summer rainfall in CMIP5 simulations. Adv. Atmos. Sci., 36, 1203-1216, https://doi.org/10.1007/ s00376-019-9066-1.

Yang, M., R. Zuo, L. Wang, and X. Chen, 2018: Simulation of land surface climate over China with RegCM4.5: Verification and analysis. Adv. Meteor., 2018, 1-14, https://doi.org/10.1155/ 2018/7960908.

Yao, Y., D. Luo, A. Dai, and I. Simmonds, 2017: Increased quasi stationarity and persistence of winter Ural blocking and Eurasian extreme cold events in response to Arctic warming. Part I: Insights from observational analyses. J. Climate, 30, 3549-3568, https://doi.org/10.1175/JCLI-D-16-0261.1.
Zhang, H., Z. Wen, R. Wu, X. Li, and R. Chen, 2019: An interdecadal increase in summer sea level pressure over the Mongolian region around the early 1990s. Climate Dyn., 52, 1935-1948, https://doi.org/10.1007/s00382-018-4228-x.

Zhang, J., H. Chen, and Q. Zhang, 2019: Extreme drought in the recent two decades in northern China resulting from Eurasian warming. Climate Dyn., 52, 2885-2902, https://doi.org/10.1007/ s00382-018-4312-2.

Zhang, S., 1984: The statistical feature of cyclones and analysis of developable weather in northern China. Plateau Meteor., 3, 83-89.

Zhang, Y., Y. Ding, and Q. Li, 2012: A climatology of extratropical cyclones over East Asia during 1958-2001. Acta Meteor. Sin., 26, 261-277, https://doi.org/10.1007/s13351-012-0301-2.

Zhou, L., H. Chen, and Y. Dai, 2015: Stronger warming amplification over drier ecoregions observed since 1979. Environ. Res. Lett., 10, 064012, https://doi.org/10.1088/1748-9326/10/6/ 064012.

,-- W. Hua, Y. Dai, and N. Wei, 2016: Mechanisms for stronger warming over drier ecoregions observed since 1979. Climate Dyn., 47, 2955-2974, https://doi.org/10.1007/s00382016-3007-9.

Zhou, Y., B. Yang, Y. Zhao, J. Jiang, A. Huang, and M. La, 2018: Effects of the ground surface temperature anomalies over the Tibetan Plateau on the rainfall over northwestern China and western Mongolia in July. Theor. Appl. Climatol., 134, 645667, https://doi.org/10.1007/s00704-017-2298-z.

Zhu, C., B. Wang, W. Qian, and B. Zhang, 2012: Recent weakening of northern East Asian summer monsoon: A possible response to global warming. Geophys. Res. Lett., 39, L09701, https:// doi.org/10.1029/2012GL051155.

Zhu, Q., J. Lin, and S. Shou, 2000: Principles of Synoptic Meteorology (in Chinese). China Meteorological Press, $535 \mathrm{pp}$. 